\author{
Universidade de São Paulo \\ Instituto de Física
}

\title{
Propriedades Eletrônicas em Nanossistemas Baseados em Nanotubos de Carbono e Grafeno
}

\author{
Alexsandro Kirch \\ Orientador: Prof. Dr. Adalberto Fazzio \\ Dissertação de mestrado apresentada ao Instituto de \\ Física para a obtenção do título de Mestre em \\ Ciências
}

Banca Examinadora:

Prof. Dr. Adalberto Fazzio (IFUSP)

Prof. Dr. Armando Corbani Ferraz (IFUSP)

Prof. Dr. Noelio Oliveira Dantas (IF-UFU)

São Paulo 
FICHA CATALOGRÁFICA

Preparada pelo Serviço de Biblioteca e Informação do Instituto de Física da Universidade de São Paulo

Kirch, Alexsandro

Propriedades eletrônicas em nanossistemas baseados em nanotubos de carbono e grafeno. São Paulo, 2014.

Dissertação (Mestrado) - Universidade de São Paulo. Instituto de Física. Depto. de Física dos Materiais e Mecânica

Orientador: Prof. Dr. Adalberto Fazzio

Área de Concentração: Física

Unitermos: 1. Física; 2. Física da matéria condensada 3. Física do estado sólido; 4. Física computacional; 5. Nanotecnologia.

USP/IF/SBI-019/2014 
"Tenha em mente que tudo que você aprende na escola é trabalho de muitas gerações. Receba essa herança, honre-a, acrescente a ela e, um dia, fielmente, deposite-a nas mãos de seus filhos."

Albert Einstein (1879-1955) 


\section{Agradecimentos}

Agradeço a todas as pessoas que me apoiaram nesta etapa importante da minha formação acadêmica. São inúmeras pessoas as quais devo meus agradecimentos, mas gostaria de agradecer em especial:

- Aos meus pais, Lirio Kirch e Iria Ludvig Kirch, pelo amor incondicional e por todo o apoio dedicado a minha formação. A eles devo essa conquista;

- Aos meus irmãos, Adalberto, Cidinei e Marli Kirch pelo apoio dado nessa caminhada;

- Ao professor Dr. Adalberto Fazzio pela dedicação tanto na orientação desse trabalho quanto na minha formação pessoal;

- Ao professor Dr. Antônio José Roque da Silva, por todas as discussões referentes ao trabalho;

- Aos pós-doutorandos José Eduardo Padilha de Sousa e Matheus Paes Lima pela colaboração nos trabalhos;

- Aos colegas do grupo SAMPA, Leonardo Abdalla, Carlos Augusto Mera, Alberto Torres, Eduardo Carvalho e Leandro Seixas pelas discussões e cafés;

- Ao meu orientador de graduação, o professor Dr. Paulo César Piquini, por ter me apoiado nessa consquista;

- A secretária Marisa Fernandes, pela atenção dada as partes burocráticas e também pela amizade;

- A FAPESP pelo apoio financeiro. 


\section{RESUMO}

Neste trabalho foram realizadas simulações computacionais para investigar as propriedades eletrônicas de nanossistemas baseados em nanotubos de carbono e grafeno por meio de cálculos de primeiros princípios. Um dos nanossistemas investigados é formado por um nanotubo de carbono acoplado a eletrodos de nanofios de paládio encapsulados. Foi mostrado que estados provenientes dos eletrodos interagem fortemente com os estados do nanotubo de carbono. Cálculos de transporte eletrônico foram realizados para investigar a potencialidade desse nanossistema em aplicações como transistor de efeito de campo. Foi mostrado que a intensidade da corrente elétrica desse nanossistema pode ser variada com o campo elétrico de gate. Outro trabalho desenvolvido no presente trabalho tem como base um nanossistema formado pelo grafeno depositado nos substratos $\mathrm{SiO}_{2}$ amorfo e $h$-BN. Foi determinada a energia de adsorção e a quantidade de carga transferida para investigar a influênicas desses substratos na adsorção da molécula de $\mathrm{H}_{2}$ pelo grafeno. Foi mostrado que a energia de adsorção da molécula de $\mathrm{H}_{2}$ adsorivda na interface grafeno/ $\mathrm{SiO}_{2}$ amorfo é menor em comparação com o grafeno suspenso ou disposto sobre o substrato $h$-BN. Além disso, a adsorção do $\mathrm{H}_{2}$ nessa região resulta em uma transferência de carga de uma ordem de grandeza maior em comparação com a adsorção no grafeno suspenso, sendo observado um deslocamento do Cone de Dirac em relação ao nível de Fermi. Esse estudo poderá contribuir para a construção de futuros sensores de $\mathrm{H}_{2}$ à base de grafeno.

Palavras-chave: transistor de nanotubo de carbono, sensor de $\mathrm{H}_{2}$ à base de grafeno, cálculos de primeiros princípios. 
ABSTRACT

In this work, ab initio calculations were performed within DFT framework to analyse electronic properties of Carbon nanotubes and grapheme nano systems. In this work, computer simulations were performed to investigate the electronic properties of nanosystems based on carbon nanotubes and graphene within DFT framework. One of these systems studied is a Carbon nanotube semiconductor coupled to encapsulated leads of Pd nanowires. It has been shown that lead's states interact strongly with the carbon nanotube states. Electronic transport calculations were performed to unfold new applications of this system, such as the field effect transistor. We noticed that charge current intensity can be tuned by electrical field. We also described the influence of amorphous $\mathrm{SiO}_{2}$ and $h$ - $\mathrm{BN}$, in $\mathrm{H}_{2}$ energy adsorption and charge transfer, where both materials are used as graphene substrates. It was shown that the latter adsorption energy in the graphene/ $\mathrm{SiO}_{2}$ is smaller than graphene $/ h$ - $\mathrm{Bn}$ and the graphene suspended itself. In fact this adsorption results in a charge transference one order greater than in the suspended graphene, which can be seen as a vertical shift of the Dirac Cone. This study may improve the construction of future $\mathrm{H}_{2}$ sensors based on graphene.

Keywords: Carbon nanotube transistor, $\mathrm{H}_{2}$ sensor, ab initio calculations. 


\section{Sumário}

1 INTRODUÇÃO.

2 GRAFENO E NANOTUBOS DE CARBONO: DESCRIÇÃO E APLICAÇÕES. $\quad$ p. 3

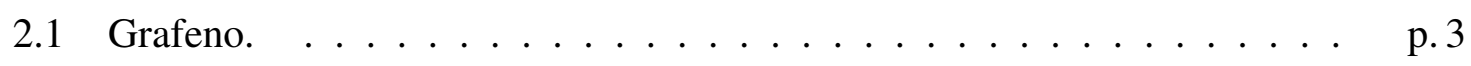

2.2 Nanotubos de carbono. . . . . . . . . . . . . . p. 5

2.3 Algumas aplicações tecnológicas. . . . . . . . . . . . p. 6

2.3.1 Transistores de efeito de campo. . . . . . . . . . p. 6

2.3.2 Sensores de moléculas. . . . . . . . . . . . p. 7

3 PROPRIEDADES ELETRÔNICAS E DE TRANSPORTE DE UM NANOTUBO DE CARBONO SEMICONDUTOR ACOPLADO A ELETRO$\begin{array}{lr}\text { DOS DE PALÁDIO ENCAPSULADO. } & \text { p. } 8\end{array}$

3.1 Metodologia. .......................... 10

3.2 Eletrodo de paládio encapsulado. . . . . . . . . . . p. 11

3.2.1 Propriedades eletrônicas do nanofio de paládio. . . . . . . . . p. 11

3.2.2 Detalhes do encapsulamento .............. p. 13 
3.3 Propriedades de transporte eletrônico. . . . . . . . . . . . . . . p. 16

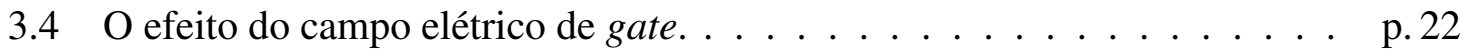

3.4.1 Variação do gap de energia do nanotubo de carbono pristino. . . . p p.22

3.4.2 O efeito do campo elétrico de gate no transporte eletrônico . . . . p. 23

3.5 Polarização da corrente elétrica. . . . . . . . . . . . . . . . p. 24

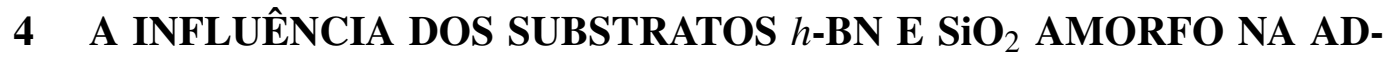
SORÇÃO DO $\mathrm{H}_{2}$ PELO GRAFENO.

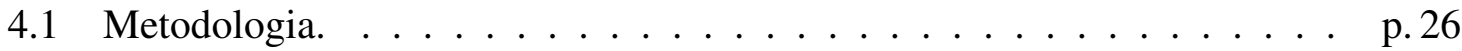

4.2 A adsorção do $\mathrm{H}_{2}$ pelo grafeno suspenso. . . . . . . . . . . . . . . . p. 27

4.3 Grafeno depositado no $\mathrm{SiO}_{2}$ amorfo e $h$-BN. . . . . . . . . . . . . p. 29

4.3.1 Caracterização do $\mathrm{SiO}_{2}$ amorfo como substrato para o grafeno. . p. 29

4.3.2 Caracterização do $h$-BN como substrato para o grafeno. . . . . . p.31

4.3.3 $\mathrm{H}_{2}$ adorvido pelo grafeno depositado no $\mathrm{SiO}_{2}$ amorfo e $h$-BN. . . p.32

4.4 A influência do campo elétrico. . . . . . . . . . . . . . . p. 36

5 CONSIDERAÇÕES FINAIS.

A TEORIA DO FUNCIONAL DA DENSIDADE p. 42

A.1 Fundamentos do problema. . . . . . . . . . . . . p. 42

A.2 Aproximação de Bohr-Oppenheimer. . . . . . . . . . . . . . . . . p.43

A.3 Teoria do Funcional da Densidade. . . . . . . . . . . . . . . . p.44

A.4 Equações de Kohn-Sham $(\mathrm{KS}) \ldots \ldots \ldots$. . . . . . . . . . . . . . . . . 44

A.5 Aproximações LDA e GGA. . . . . . . . . . . . . . . . . . p. p 46 
A.6 Teoria do pseudopotencial. . . . . . . . . . . . . . . . . p. 47

A.7 Funções da base. . . . . . . . . . . . . . . . . . . . . p. 50

B TÉCNICA DAS FUNÇÕES DE GREEN FORA DO EQUILÍBRIO. p. p2

B.1 Funções de Green Fora do Equilíbrio. . . . . . . . . . . . . . p p.53

B.1.1 Função espectral. . . . . . . . . . . . . . . . . p.55

B.1.2 Função de onda resposta. . . . . . . . . . . . . . . . p.57

B.1.3 Densidade de portadores de carga. . . . . . . . . . . p. 58

B.1.4 Corrente de probabilidade. . . . . . . . . . . . . . p.59

B.2 Códigos computacionais utilizados nas simulações. . . . . . . . . . p.62

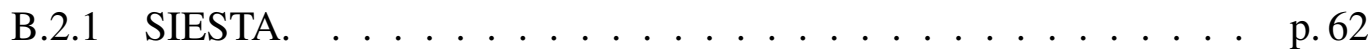

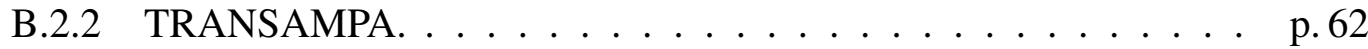

$\begin{array}{llr}\text { C PROGRAMA AWIREK p. } 63 & \text { p }\end{array}$

$\begin{array}{lr}\text { Referências Bibliográficas } & \text { p. } 64\end{array}$ 
Capítulo $1 \longrightarrow$

\section{INTRODUÇÃO.}

No ano de 1991 foram obtidos e caracterizados os primeiros nanotubos de carbono por Iijima et al.(1). Nanotubos de carbono são estruturas cilíndricas com diâmetro da ordem de nanômetros $\left(10^{-9} \mathrm{~m}\right)$ e comprimento que pode chegar à ordem de micrômetros $\left(10^{-6} \mathrm{~m}\right)$. No ano de 2004, Geim e Novoselov(2) isolaram o grafeno por meio da esfoliação mecânica de uma amostra de grafite, utilizando uma fita adesiva. Os pesquisadores receberam prêmio Nobel de Física no ano de 2010 pela obtenção e caracterização desse material. O grafeno possui uma rede tipo "favo de mel" com espessura de um único átomo de carbono. Sua estrutura eletrônica é diferente da dos materiais metálicos e semicondutores usuais, sendo destacada a relação linear entre a energia e o momento.

Nanotubos de carbono (ver Capítulo 2) são materiais que podem ser utilizados para a construção de transistores de efeito de campo, pois suas propriedades eletrônicas são significativamente modificadas pelo campo elétrico de gate (3). Além disso, eles apresentam mobilidade elétrica ${ }^{1}$ vinte vezes maior que o silício $(4,5,6)$. Atualmente, os dispositivos eletrônicos consistem em bilhões de transistores desse material (7). Processadores com maior capacidade de processamento podem ser construídos a partir da diminuição dos seus componentes $(8,9)$. Franklin et al.(10) mostraram ser possível construir transistores de

\footnotetext{
${ }^{1} \mathrm{~A}$ mobilidade elétrica $v$ de uma partícula é definida como a razão entre a velocidade de deriva $v_{d}$ e o módulo do campo elétrico $|E|$, ou seja: $v=v_{d} /|E|$.
} 
efeito de campo à base de nanotubos de carbono de comprimentos de gate menores que os atuais transistores à base de silício. Tendo os resultados dessa pesquisa como motivação, no presente trabalho foram investigadas as propriedades eletrônicas de um nanossistema formado por um nanotubo de carbono semicondutor acoplado a eletrodos metálicos, formados por nanofios de paládio encapsulados. Cálculos de transporte eletrônico foram realizados para investigar a potencialidade desse nanossistema em aplicações como transistor de efeito de campo. Os resultados deste estudo são apresentados no Capítulo 3.

Outro nanossistema investigado nesta pesquisa tem como base o grafeno. As propriedades eletrônicas do grafeno são alteradas quando moléculas são nele adsorvidas, possibilitando a construção de sensores de gases, capazes de detectar moléculas individuais (11). No entanto, as propriedades eletrônicas do grafeno não são alteradas significativamente com a adsorção de moléculas como o $\mathrm{H}_{2}$ e o $\mathrm{O}_{2}$ (12). Porém, Silvestre et al.(13) mostram experimentalmente ser possível detectar o $\mathrm{O}_{2}$ com sensores à base de grafeno estando esse depositado no substrato $\mathrm{SiO}_{2}$. A hipótese defendida pelo autor é que o substrato $\mathrm{SiO}_{2}$ influencie na transferência de carga entre a molécula e o grafeno, quando o $\mathrm{O}_{2}$ está adsorvido na região intersticial. Tendo os resultados dessa pesquisa como motivação, no presente trabalho foram determinadas grandezas físicas como energia de adsorção e quantidade de carga transferida para investigar a influência dos substratos $\mathrm{SiO}_{2}$ amorfo e $h$-BN na adsorção do $\mathrm{H}_{2}$ pelo grafeno. Este estudo, apresentado no Capítulo 4, poderá contribuir para a construção de futuros sensores de $\mathrm{H}_{2}$ à base de grafeno.

As propriedades eletrônicas desses dois nanossistemas foram investigadas por meio de simulações computacionais, fazendo uso do formalismo da Teoria do Funcional da Densidade (DFT) (ver Apêndice A). Simulações de transporte eletrônico foram realizadas por meio do formalismo da DFT acoplado à técnica das Funções de Green Fora do Equilíbrio (NEGF) (ver Apêndice B). Simulações computacionais utilizando essas técnicas e teorias possuem caráter preditivo aos resultados experimentais, além de permitir o estudo de sistemas em escala atômica (14). 
$\Gamma_{\text {Capítulo }} 2$

\section{GRAFENO E NANOTUBOS DE}

\section{CARBONO: DESCRIÇÃO E}

\section{APLICAÇÕES.}

\subsection{Grafeno.}

O grafite é formado por um conjunto de estruturas bidimensionais empilhadas. Uma única camada destas isolada é denomidada de grafeno. A separação deste material só foi conseguida experimentalmente em 2004 por Novoselov et al.(15). Nunca antes uma estrutura tão fina foi obtida experimentalmente. Segundo a teoria de Peierls(16) e Landau(17), cristais bidimensionais são termodinamicamente instáveis e não poderiam existir. A justificativa para a existência do grafeno é de que as fortes ligações entre os átomos de carbono permitem a estabilidade do cristal.

A estrutura cristalina do grafeno é constituida de uma rede hexagonal com dois átomos na base (A e B), conforme apresentada na Figura 2.1(a). Átomos vizinhos no grafeno estão

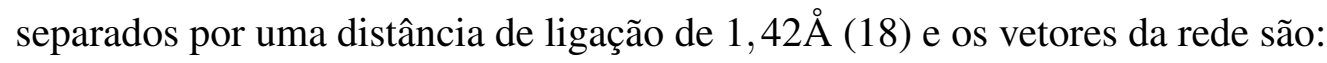

$$
\vec{a}_{1}=\frac{a}{2} \hat{x}+\frac{\sqrt{3} a}{2} \hat{y} \quad \vec{a}_{2}=-\frac{a}{2} \hat{x}+\frac{\sqrt{3} a}{2} \hat{y}
$$


onde $a$ é o parâmetro de rede. Os vetores primitivos da rede recíproca do grafeno são:

$$
\vec{b}_{1}=\frac{2 \pi \sqrt{3}}{3 a} \hat{x}+\frac{2 \pi}{a} \hat{y} \quad \vec{b}_{1}=-\frac{2 \pi \sqrt{3}}{3 a} \hat{x}+\frac{2 \pi}{a} \hat{y},
$$

de modo que $\vec{a}_{i} \cdot \vec{b}_{j}=2 \pi \delta_{i j}$.

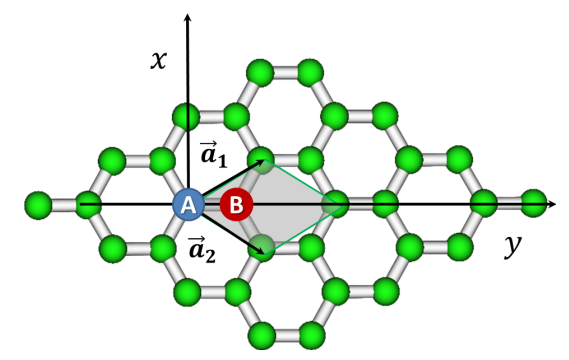

(a) Rede do grafeno.

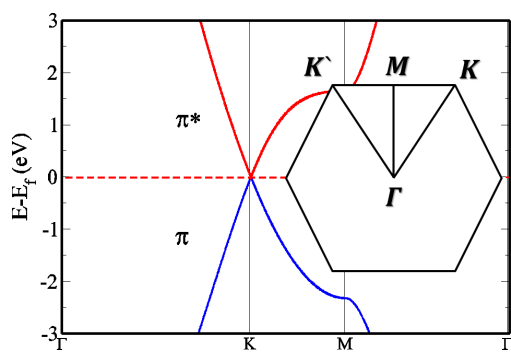

(b) Estrutura de bandas de energia.

Figura 2.1: (a) A rede do grafeno é uma hexagonal com dois átomos na base (A e B); (b) bandas de energia do grafeno no entorno do nível de Fermi $\left(E_{f}\right)$, resultante da interção entre os orbitais $\pi$ de átomos de carbono vizinhos. Na parte direita do gráfico é apresentada a primeira zona de Brillouin do grafeno, destacando os pontos de alta simetria.

O carbono possui a distribuição eletrônica $1 s^{2} 2 s^{2} 2 p^{2}$. Os elétrons do orbital $1 s$ estão ligados ao núcleo, ao passo os elétrons dos orbitais $2 s$ e $2 p$ são elétrons de valência e participam diretamente das propriedades químicas e físicas dos materiais à base de carbono (18). Os orbitais do carbono misturam-se no grafeno, formando orbitais híbridos $\sigma$ e $\pi$.A ligação química entre os átomos de carbono no grafeno é atribuída à interação entre os orbitais $\sigma$. Interações entre orbitais $\pi$ também ocorrem, resultando em uma relação linear entre energia e momento no entorno do nível de Fermi (19). O espectro de energia desa região é formado pelos estados $\pi^{*}$ (banda de condução) e estados $\pi$ (banda de valência), conforme apresentado na Figura 2.1(b). Esses dois estados tocam-se em seis pontos equivalentes na zona de Brillouin, sendo esses denominados pontos de Dirac. Como o contato entre as a bandas de condução e de valência ocorre apenas nos pontos de Dirac, o grafeno é classificado como um semicondutor de gap zero ${ }^{1}$. Próximo ao nível de Fermi, as bandas de energia podem ser descritas por uma função linear $E(k)= \pm \hbar v_{F} k$, onde $v_{F}\left(v_{F} \approx 10^{6} \mathrm{~m} / \mathrm{s}\right)$ é a velocidade de

\footnotetext{
${ }^{1}$ Suas bandas de valência estão totalmente preenchidas, sendo essa uma característica de semicondutor. Para um aprofundamento no tema, ver a referência (19).
} 
Fermi. Essa relação de dispersão é semelhante à equação da energia relativística de Dirac, no entanto, a massa de repouso é nula e a velocidade é $v_{F}$. Os portadores de carga no grafeno são descritos por funções de onda de duas componentes, cada uma relacionada à respectiva subrede (A e B). Descrição semelhante é feita em sistemas de spin como, por exemplo, o gás de Fermions. Uma vez que possuem as propriedades de Fermions e são descritos pela equação relativística de Dirac, os portadores de carga no grafeno acabam sendo denominados Fermions de Dirac.

\subsection{Nanotubos de carbono.}

A estrutura física de um nanotubo de carbono pode ser compreendida a partir do enrolamento de uma rede tipo "favo de mel" como a do grafeno. Diferentes estruturas cilíndricas podem ser formadas variando-se a direção de enrolamento em relação à rede deste material. A direção na qual a rede do grafeno é enrolada é especificada pelo vetor quiral:

$$
\vec{C}_{h}=n \vec{a}_{1}+m \vec{a}_{2}
$$

onde $n$ e $m$ são as respectivas projeções do vetor quiral nos vetores da base $\vec{a}_{1}$ e $\vec{a}_{2}$, conforme apresentado na Figura 2.2(a).

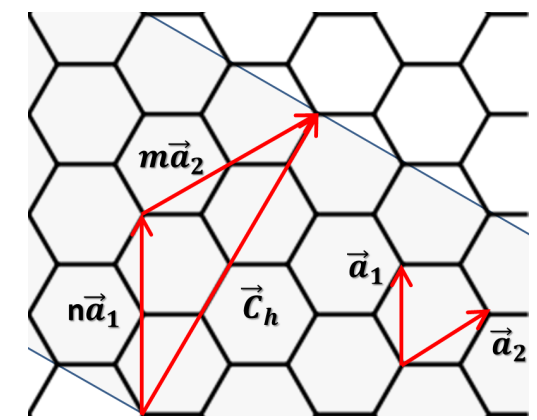

(a) Vetor quiral.

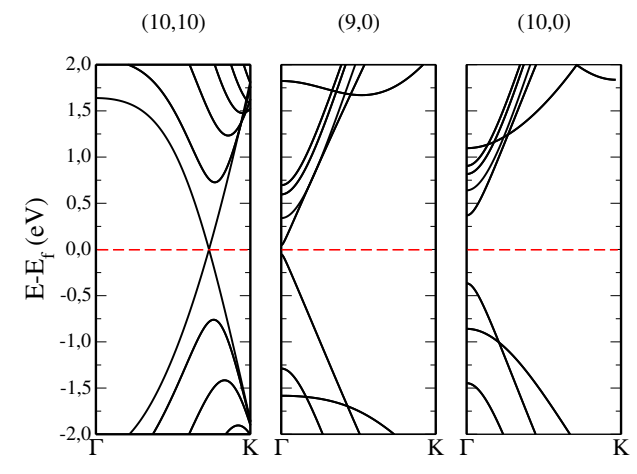

(b) Estrutura de bandas de energia.

Figura 2.2: (a) Vetores da rede e quiral $\vec{C}_{h}$ dos nanotubos de carbono; (b) estruturas de bandas de energia do um nanotubo de carbono $(n, m)=(8,0),(10,10)$ e $(10,0)$, respectivamente. 
A nomenclatura dos nanotubos é dada em função dos números inteiros $n$ e $m$ : 1) se $n=m \neq 0$ o nanotubo é tipo armchair; 2) se $n \neq 0$ e $m=0$, esse nanotubo é do tipo zig-zag; 3) se $n \neq m \neq 0$, o nanotubo é do tipo quiral. As propriedades eletrônicas dos nanotubos de carbono variam com a sua helicidade (18): nanotubos de carbono tipo armchair são metálicos, assim como os nanotubos tipo zig-zag que satisfazem a relação $|n-m|=3 k$ (onde $k$ é um número inteiro). Nanotubos tipo zig-zag que satisfazem a relação $|n-m|=3 k \pm 1$ são semicondutores. Um diagrama de bandas de energia de um nanotubo armchair, zig-zag metálico e semicondutor é apresentado na Figura 2.2(b) ${ }^{1}$. O gap de energia dos nanotubos de carbono semicondutores varia com o diâmetro e pode chegar até 1, $0 \mathrm{eV}$ (22).

\subsection{Algumas aplicações tecnológicas.}

\subsubsection{Transistores de efeito de campo.}

Um transistor de efeito de campo é um componente eletrônico que permite o controle da intensidade da corrente elétrica entre os eletrodos (fonte e dreno) por meio de um campo elétrico de gate aplicado em um material cujas propriedades eletrônicas são modificadas por este campo. As propriedades eletrônicas do grafeno (23) e dos nanotubos de carbono (3) são influenciadas pelo campo elétrico. Como já foi demonstrado experimentalmente, o grafeno pode ser utilizado na construção de transistores de rádio frequência ${ }^{2}$ (24). Porém, para a construção de transistores lógicos, variações significativas nas propriedades eletrônicas do material são necessárias para a obtenção de 0 (corrente off) e 1 (corrente on). Relações entre as intensidades das correntes $I_{o n} / I_{o f f}>10^{3}$ são requeridas (25) para a construção de transistores lógicos. Essa relação é maior nos nanotubos de carbono semicondutores se comparada ao grafeno e, por isso, nanotubos de carbono são materiais que possuem potencial maior para a construção de transistores lógicos (26).

\footnotetext{
${ }^{1}$ Para um aprofundamento no tema, ver as referências (20) e (21).

${ }^{2}$ Transistores de rádio frequência operam na faixa de $3 \mathrm{kHz}$ a $300 \mathrm{GHz}$.
} 


\subsubsection{Sensores de moléculas.}

Trabalhos experimentais $(11,27,28,29,30,31,32)$ têm demonstrado o potencial do grafeno para a construção de sensores de gases. A adsorção de moléculas no grafeno pode ser observada indiretamente pelo deslocamento do ponto de neutralidade de carga do grafeno nas medidas de transporte eletrônico (13). Com a transferência de carga entre a molécula e o grafeno, há um deslocamento do nível de Fermi em relação ao ponto de Dirac (ver Figura 2.3): se a carga é transferida da molécula para o grafeno, há um aumento no nível de Fermi do grafeno em relação ao ponto de Dirac (dopagem tipo $n$ ); se a carga é transferida do grafeno para a molécula, há uma diminuição do nível de Fermi em relação ao mesmo ponto (dopagem tipo $p$ ).

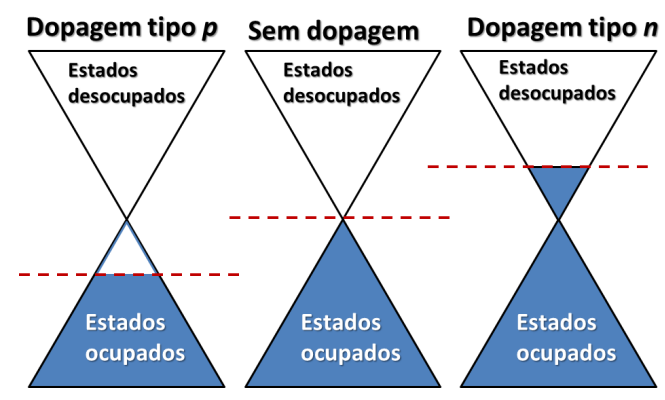

Figura 2.3: Deslocamento do nível de Fermi como resultado da transferência de carga entre a molécula e o grafeno. Potenciais de gate podem ser utilizados para deslocar o nível de Fermi até o ponto de Dirac (ponto de neutralidade de carga).

Com um potencial de gate, a energia do nível de Fermi do sistema pode ser deslocada para mais ou para menos em relação ao ponto de Dirac (2). Para um determinado potecial de gate, o nível de Fermi passa pelo ponto de Dirac (ponto de neutralidade de carga). Assim, a carga transferida e o pontencial de gate necessário para atingir o ponto de neutralidade de carga estão relacionados. 
Capítulo 2

\section{PROPRIEDADES ELETRÔNICAS E DE}

\section{TRANSPORTE DE UM NANOTUBO DE}

\section{CARBONO SEMICONDUTOR}

\section{ACOPLADO A ELETRODOS DE}

PALÁDIO ENCAPSULADO.

Devido à demanda de dispositivos eletrônicos que apresentam menor dissipação de energia e tamanho para a construção de aparelhos eletrônicos, como celulares e computadores, transistores com comprimentos de gate abaixo de 10nm serão requeridos para a próxima década, conforme destacado por Ieong et al.(8). Em 2012, Franklin et al.(10) produziram um transistor à base de nanotubos de carbono com comprimento de gate menor que o encontrado nos atuais transistores à base de silício. Esse e os trabalhos posteriores $(33,34)$ mostram o potencial dos nanotubos de carbono para a construção de transistores de efeito de campo com dimensões nanométricas.

Nanotubos de carbono semicondutores são interessantes para a construção de transistores de efeito de campo, pois suas propriedades de transporte são significativamente modificadas pelo campo elétrico de gate, principalmente devido a variação do seu gap de energia 
(3). Na construção de um transitor de efeito de campo, um nanotubo de carbono semicondutor é conectado a eletrodos metálicos. Como é sabido, a junção metal-semicondutor pode resultar em uma relação entre a diferença de potencial elétrico de bias $^{1}$ e a intensidade da corrente elétrica com caráter tanto ôhmico (em que há uma relação linear entre a intensidade corrente elétrica e a diferença de potencial) quanto retificador (conduzindo corrente elétrica na polarização direta e não conduzindo na polarização reversa devido à existência de uma barreira Schottky) (35). O caráter ôhmico ou retificador do contato metal-nanotubo de carbono é determinado, por exemplo, pelo tipo de metal utilizado na junção (36). Para a construção de transistores de efeito de campo de alto desempenho, é desejável que o contato tenha caráter ôhmico ao invés de retificador (37). Como destacado tanto em trabalhos teóricos (36) quanto experimentais $(38,39,40,41)$ o paládio proporciona um contato com caráter próximo ao ôhmico quando em contato com um nanotubo de carbono semicondutor.

A conexão do metal ao nanotubo de carbono pode ser realizada por meio da deposição do nanotubo sobre o metal (36) ou inserido em metais líquidos como o Mercúrio (Hg) (42); embutido no metal $(43,44)$ ou confinado entre eletrodos metálicos (45). A inserção de metais nos nanotubos de carbono é outra possibilidade e, embora a síntese desse tipo de sistema seja possível(46), as suas propriedades de transporte eletrônico ainda não são bem compreendidas. Os metais inseridos nos nanotubos de carbono estão protegidos da oxidação que diminui a condutância nos metais $(47,48)$. A proteção contra a oxidação dos metais é uma vantagem desse sistema em relação a outros tipos de conexões citadas anteriormente. Assim, esse sistema poderia ser utilizado como eletrodo para a construção de futuros transistores de efeito de campo de alto desempenho à base de nanotubos de carbono.

Tendo como motivação os resultados experimentais de Franklin et al.(10), simulações computacionais poderiam contribuir para compreender melhor as propriedades de transporte eletrônico dos nanotubos de carbono e as suas potencialidades em aplicações como transistores de efeito de campo. Assim, no presente trabalho foram realizadas simulações com-

\footnotetext{
${ }^{1}$ Diferença de potencial elétrico entre a fonte e o dreno
} 
putacionais para investigar as propriedades eletrônicas e de transporte de um nanossistema formado por um nanotubo de carbono semicondutor $(n, m)=(10,0)$ (região central), acoplado a eletrodos metálicos formados por um nanofio de paládio encapsulado. O esquema do nanossistema investigado é apresentado na Figura 3.1.

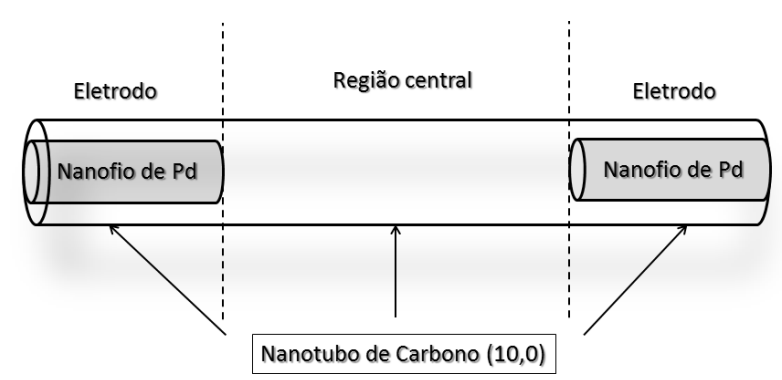

Figura 3.1: Representação esquemática do nanossistema formado por um nanotubo de carbono $(10,0)$ acoplado a eletrodos de paládio encapsulado.

O objetivo do trabalho é investigar as propriedades eletrônicas e de transporte desse nanossistema. A sua potencialidade em aplicações como transistores de efeito de campo pode ser investigada ao considerar o efeito do campo elétrico de gate nas simulações computacionais de transporte eletrônico. Esse trabalho poderá contribuir para a construção de futuros transistores de efeito de campo de alto desempenho à base de nanotubos de carbono.

\subsection{Metodologia.}

As propriedades eletrônicas do nanossistema foram investigadas por meio de simulações computacionais fazendo uso do formalismo da Teoria do Funcional da Densidade (Apêndice A), estando ele implementado no codigo SIESTA (49). Simulações de transporte eletrônico foram realizadadas com o Formalismo da Teoria do Funcional da Densidade, acoplado a técnica das Funções de Green Fora do Equilíbrio -Apêndice B - como implementado no código TRANSAMPA. A Teoria do Funcional da Densidade é uma teoria da mecânica quântica utilizada para resolver equações tipo Schrödinger para sistemas de muitos corpos acoplados em escala atômica. Nessa teoria a variável principal deixa de ser a função de onda e passa a ser a densidade eletrônica. Já por meio da técnica das Funções de 
Green Fora do Equilíbrio é possível determinar a corrente elétrica em nanossistemas devido a um transporte balístico de portadores de cargas.

Nas simulações computacionais foram utilizados pseudopotenciais de norma conservada (50) para descrever a interação entre os caroços iônicos e os elétrons de valência, sendo esses elétrons de valência representados por um conjunto de base tipo duplo- $\zeta$, mais uma função de polarização. Além disso, um mesh cut-off de 300Ry foi utilizado para delimitar o tamanho da base. Utilizou-se um número de pontos $k$ para representar a zona de Brillouin de forma que a convergência na energia total fosse menor ou igual a $3 \mathrm{meV}$ por célula unitária, sempre utilizando a amostragem de Monkhorst e Pack(51). Na otimização das geometrias do sistema foi adotado o critério de que as forças resultantes sobre os átomos são menores que $0,01 \mathrm{eV} / \AA$.

\subsection{Eletrodo de paládio encapsulado.}

\subsubsection{Propriedades eletrônicas do nanofio de paládio.}

O pseudopotencial dos átomos de paládio foi gerado usando a configuração eletrônica $4 d^{9} 5 s^{1} 5 p^{0}$. Essa configuração reproduz melhor as características do bulk paládio conforme Aguilera-Granja et al.(52). Um estudo sistemático da otimização dos raios de corte do pseudopotencial foi realizado com base nos parâmetros dos mesmos autores no sentido de obter a melhor descrição do bulk paládio. Foram obtidos os raios de corte 2,0; 2,2; 2,4 e 2,4 a.u (unidades atômicas) para os orbitais $s, p, d$ e $f$, respectivamente.

A escolha do funcional para a energia de troca e correlação está baseada nos estudos de Alexandre et al.(53) que mostram que o paládio (bulk) apresenta um momento magnético resultante nulo, utilizando o funcional para a energia de troca e correlação LDA - em concordância com os resultados experimentais. Já nas simulações computacionais em que o funcional para a energia e troca e correlação utilizado é o GGA, o bulk paládio apresenta um momento magnético resultante finito, descrevendo de forma inadequada as propriedades 
eletrônicas desse metal.

Grandezas como a constante de rede, momento magnético, potencial químico e distância interatômica foram determinadas a fim de comparar a qualidade do pseudopotencial gerado na descrição do bulk. Alguns parâmetros - como a constante de rede e o momento magnético — determinados com o pseudopotencial gerado e os parâmetros encontrados na literatura(54) são comparáveis em termos absolutos, conforme os dados apresentados na Tabela 3.1. A diferença na energia de coesão obtida na descrição desse sistema com funcional para a energia de troca e correlação LDA se deve ao fato de esse funcional superstimar a energia total do átomo isolado (55).

\begin{tabular}{llr}
\cline { 2 - 3 } Grandeza & LDA & Referência (54) \\
\hline Parâmetro de rede $(\AA)$ & 3,89 & 3,89 \\
Energia de coesão $(\mathrm{eV})$ & 4,99 & 3,89 \\
Bulk Modulus $(\mathrm{GPa})$ & 200 & 180 \\
Momento Magnetico $\left(\mu_{B}\right)$ & 0,0 & 0,0 \\
\hline
\end{tabular}

Tabela 3.1: Comparação entre os parâmetros do bulk paládio descritos com o pseudopotencial gerado e os parâmetros encontrados na literatura.

As coordenadas de um nanofio - apresentado na Figura 3.2(a) — foram geradas a partir do bulk paládio por meio do programa AwireK (Apêndice C). Esse nanofio possui a direção de crescimento [111], de acordo com os resultados de trabalhos experimentais (56), que mostram que nanofios de paládio crescem preferencialmente nessa direção. Esse nano-

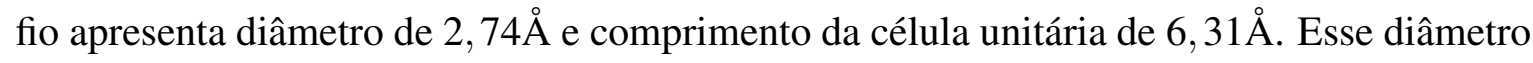
foi escolhido devido às suas dimensões físicas que permitem a sua inserção no nanotubo de carbono $(10,0)$ (diâmetro de 7,94^̊). Nanofios estruturados ultrafinos de paládio (abaixo de $10 \mathrm{~nm}$ de diâmetro) já são obtidos experimentalmente $(57,58)$ por meio da técnica de CVD (Chemical Vapor Deposition). 


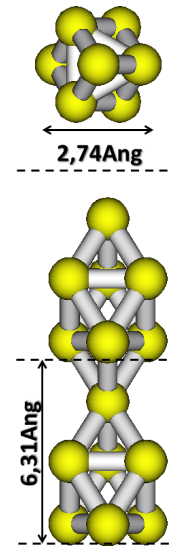

(a) Nanofio.
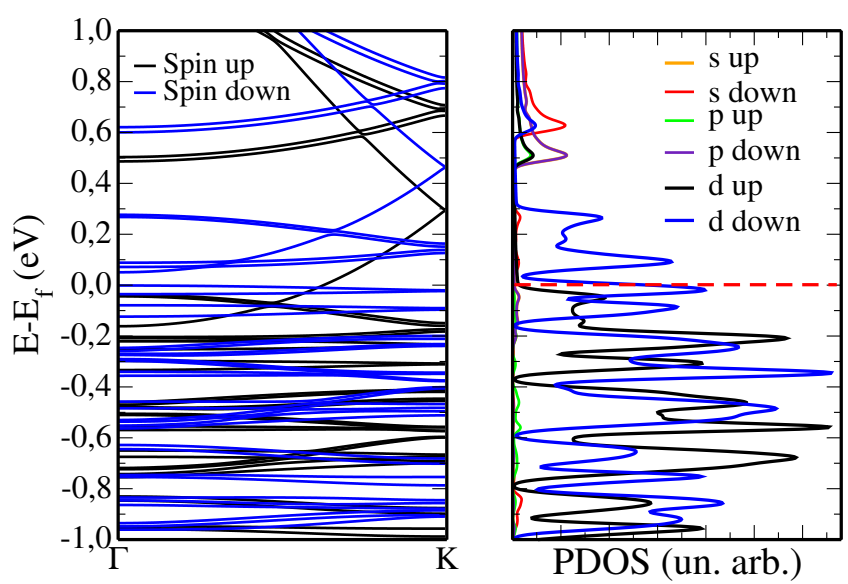

(b) Estrutura de bandas e PDOS do nanofio de paládio.

Figura 3.2: (a) Representação pictórica do nanofio de paládio gerado pelo código AwireK; (b) estrutura de bandas e a respectiva PDOS do nanofio de paládio.

O nanofio de paládio gerado possui um momento magnético resultante finito $(\mu \sim$ $0,37 \mu_{B} /$ átomo $)^{1}$ na configuração de equilíbrio, conforme os resultados obtidos no presente trabalho. Momentos magnéticos resultantes finitos são observados experimentalmente (59) nos nanofios de paládio, sendo isso explicado pela redução dos graus de liberdade (passando do bulk tridimensional para o nanofio unidimensional) e do número de ligações químicas, favorecendo uma maior localização dos estados eletrônicos (60). Estados localizados são observados principalmente na banda de valência, sendo eles provenientes dos orbitais $d$, como pode ser confirmado pelo gráfico da Figura 3.2(b). Além disso, estados cruzando o nível de Fermi caracterizam esse nanofio de paládio como sendo metálico.

\subsubsection{Detalhes do encapsulamento}

Existe uma diferença entre o comprimento das células unitárias do nanofio de paládio e do nanotubo de carbono. A fim de representar os dois sistemas pela mesma célula unitária, foram inicialmente consideradas, respectivamente, três e duas células unitárias do nanotubo de carbono e do nanofio de paládio. Com essa relação, existe ainda uma divergência de 1,8\% entre o comprimento das células unitárias do nanofio de paládio e do nanotubo de carbono.

\footnotetext{
${ }^{1} \mu_{B}=9,274 \times 10^{-24} J / T$ é o magneton de Bohr.
} 
Com o aumento comprimento da célula unitária do nanofio de paládio em 1,8\%, é possível representar os dois sistemas pela mesma célula unitária. Nessa situação, há um uma variação do momento magnético resultante de 0,37 para $0,40 \mu_{B} /$ átomo, sendo que variações no momento magnético devido ao parâmetro de rede já foram previstas teoricamente(61). Não foram observadas variações significativas na estrutura de bandas do nanofio devido ao aumento da célula unitária do nanofio de paládio. Uma representação pictórica do sistema formado pelo nanofio de paládio encapsulado no nanotubo de carbono $(10,0)$ é apresentada na Figura 3.3.
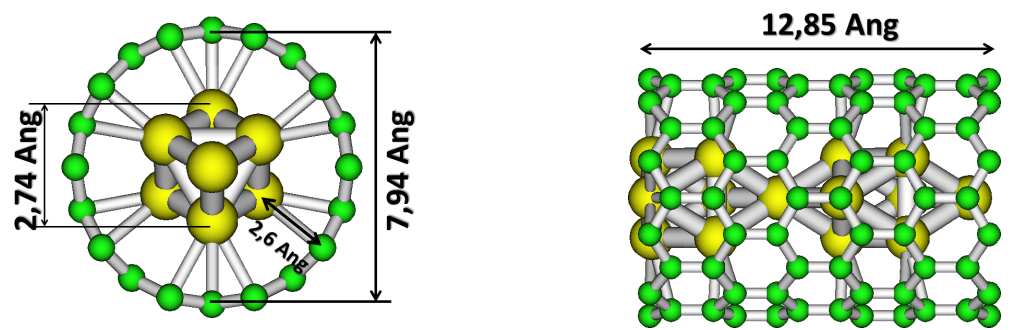

Figura 3.3: Representação pictórica do eletrodo formado pela inserção de um nanofio de paládio no nanotubo de carbono $(10,0)$.

A inserção do nanofio de paládio no nanotubo de carbono $(10,0)$ é energeticamente favorável em relação aos sistemas isolados. Para concluir isso, foi determinada a energia de inserção $E_{\text {in }}$ (por átomo de paládio) segundo a equação:

$$
E_{\text {in }}=\frac{E_{D}-E_{\infty}}{N_{P d}}
$$

onde $E_{\infty}$ é a energia do sistema em que o nanotubo de carbono e o nanofio de paládio (ambos finitos) estão separados por uma distância suficientemente grande para que a influência das interações na energia total do sistema possa ser desprezada ${ }^{1} ; E_{D}$ é a energia do sistema estando o nanofio a uma distância ${ }^{2} D$ do nanotubo conforme especificado na Figura 3.4(a); e $N_{P d}$ é o número de átomos de paládio. A curva de $E_{i n}$ em função de $D$ é apresentada na Figura 3.4(a). De acordo com os resultados apresentados nessa figura, não existe uma barreira

\footnotetext{
${ }^{1}$ Foi considerada a distância de separação de 20,0 $\AA$.

${ }^{2}$ A distância $D$ foi determinada a partir de um átomo de paládio de uma das extremidades do nanofio e o primeiro átomo de carbono de uma das bordas do nanotubo.
} 
de potencial $\left(E_{\text {in }}>0\right)$ para a inserção do nanofio de paládio no nanotubo de carbono $(10,0)$. A possibilidade de inserção dos metais nos nanotubos foi demostrada experimentalmente (62) e é explicada teoricamente pelo fenômeno da capilaridade ${ }^{1}$ (64).

O sistema formado pelo nanofio de paládio inserido no nanotubo de carbono $(10,0)$ possui caráter metálico, pois há estados cruzando o nível de Fermi, como pode ser observado no gráfico da estrutura de bandas de energia apresentado na Figura 3.4(b). Portanto, esse sistema pode ser utilizado como eletrodo para a injeção de cargas na região de espalhamento do sistema formado pelo nanotubo de carbono $(10,0)$ (sem o nanofio de paládio).

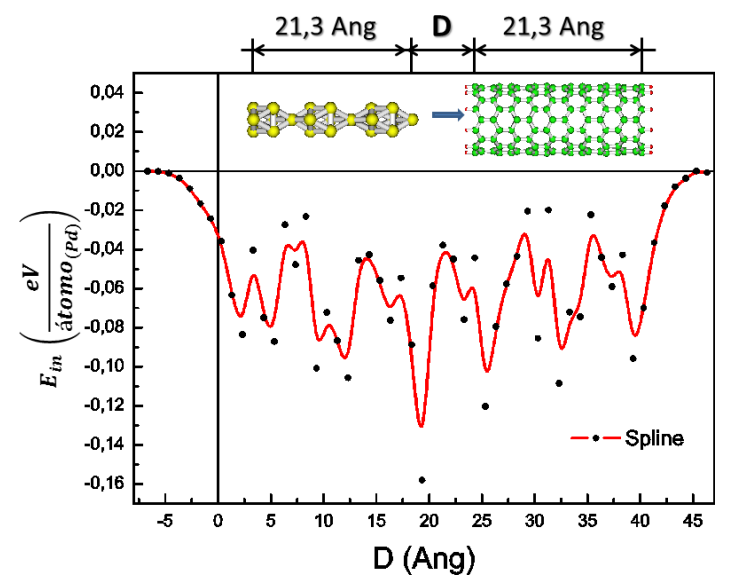

(a) Energia de inserção.

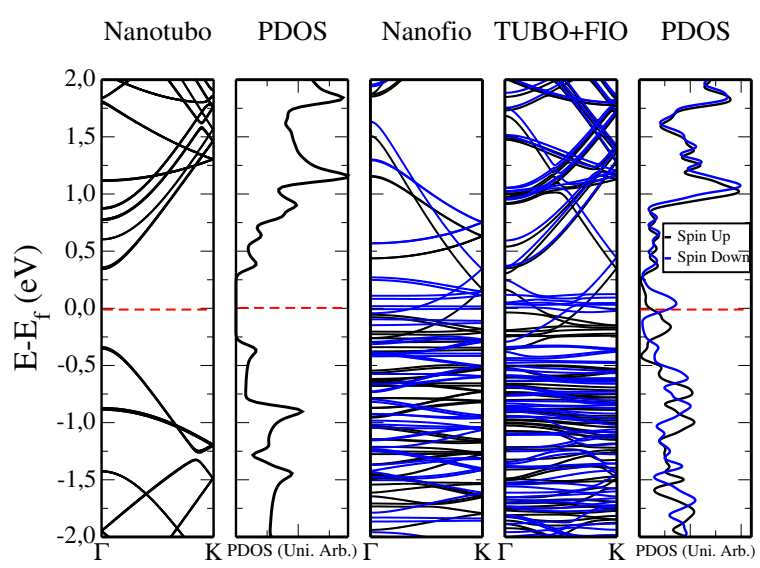

(b) Bandas de energia e PDOS.

Figura 3.4: (a) Energia de inserção de um nanofio de paládio em um nanotubo de carbono $(10,0)$ finito em função da distância $D$; (b) estrutura de bandas de energia do nanotubo, nanofio e do eletrodo, com as respectivas densidade de estados projetada nos átomos de carbono.

Carga elétrica é transferida do nanofio de paládio para o nanotubo de carbono $(10,0)$. Isso é mostrado por meio da integração da densidade de estados projetada (PDOS) nos átomos de carbono ${ }^{2}$. Uma quantidade de carga elétrica $Q_{T}=4,8 \times 10^{-3} e /($ átomo de C) é transferida do nanofio de paládio para o nanotubo de carbono $(10,0)$, resultando em uma dopagem tipo $n$. Segundo Kulshrestha et al.(65), a transferência de carga entre o metal e

\footnotetext{
${ }^{1}$ Para um aprofundamento no tema, ver a referência (63).

${ }^{2} \mathrm{~A}$ integral da densidade de estados projetada (PDOS) nos átomos de carbono — no espectro de energia de $-\infty$ até o nível de Fermi $\left(E_{f}\right)$ do sistema - resulta na carga total de valência dos átomos de carbono, ou seja, $q=\int_{-\infty}^{E_{f}} \operatorname{PDOS}(E) d E$. A diferença entre a carga total do nanotubo com e sem o nanofio de paládio resulta na carga transferida $Q_{T}$, ou seja $\left.Q_{T}=q_{C\left(s e m_{-} P d\right.}-q_{C(\text { com_}} P d\right)$.
} 
o nanotubo de carbono sugere que há uma hibridização dos estados do metal com os do nanotubo, sendo isso demonstrado para o níquel (Ni) e o ferro (Fe) encapsulado em um nanotubo de carbono. Segundo o mesmo autor, a hibridização dos estados possibilita a transferência de cargas entre o nanofio e o nanotubo sem haver uma barreira de potencial dificultando a transferência.

Com a inserção do nanofio de paládio no nanotubo de carbono há uma redução do momento magnético do sistema. Dentro do nanotubo, o momento magnético resultante é reduzido para $\mu=0,33 \mu_{B} /$ (átomo de paládio), uma variação de $17,5 \%$ em relação ao momento magnético resultante do fio isolado.

\subsection{Propriedades de transporte eletrônico.}

O eletrodo descrito na seção anterior é acoplado a uma região semicondutora (denominada região central) formada pelo nanotubo de carbono $(10,0)$ (sem a presença do nanofio de paládio). Para garantir um comportamento pristino dos eletrodos, foi considerada uma região adicional no sistema, denominada de região de buffer. O esquema do sistema investigado é apresentado na Figura 3.5(a). A fim de investigar a influência do comprimento $D$ da região central no transporte eletrônico, foram aqui considerados comprimentos $D=1,61 \mathrm{~nm}$ ( sistema $S 1)$ e $D=2,81 \mathrm{~nm}($ sistema $S 2)$.

No estudo das propriedades de transporte eletrônico de um nanossistema por meio de simulações computacionais, há o interesse na determinação da transmitância $T(E)$ do sistema. A transmitância pode ser interpretada como a probabilidade que um portador de carga com energia $E$ possui de atravessar o sistema balisticamente ${ }^{1}$. A curva $T(E)$ para valores no entorno do nível de Fermi do eletrodo é apresentada na Figura 3.5(b). A transmitância do eletrodo evidencia o seu caráter metálico ao apresentar uma transmitância finita (não nula) no entorno do nível de Fermi. Uma comparação da estrutura de bandas de energia e a trans-

\footnotetext{
${ }^{1}$ Mais detalhes deste assunto são encontrados no Apêndice B.
} 
mitância do eletrodo mostra que há uma correspondência entre elas: na região do espectro de energia onde há estados de spin up, por exemplo, há uma transmitância finita de carga com essa polarização de spin e onde esses estados não estão presentes, a transmitância é nula. Cada estado contribui com uma transmitância de $100 \%$ para cada valor de $E$, como é esperado, uma vez que o eletrodo apresenta comportamento pristino. Além disso, a transmitância apresenta valores diferentes para cada canal de spin gerado pelo momento magnético resultante finito do eletrodo.

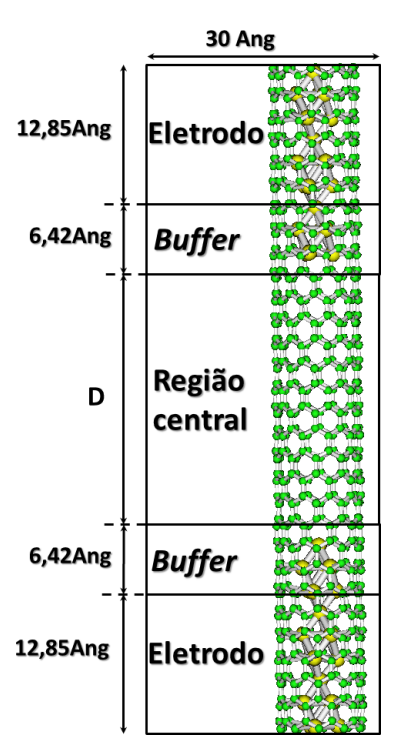

(a) Sistema investigado.

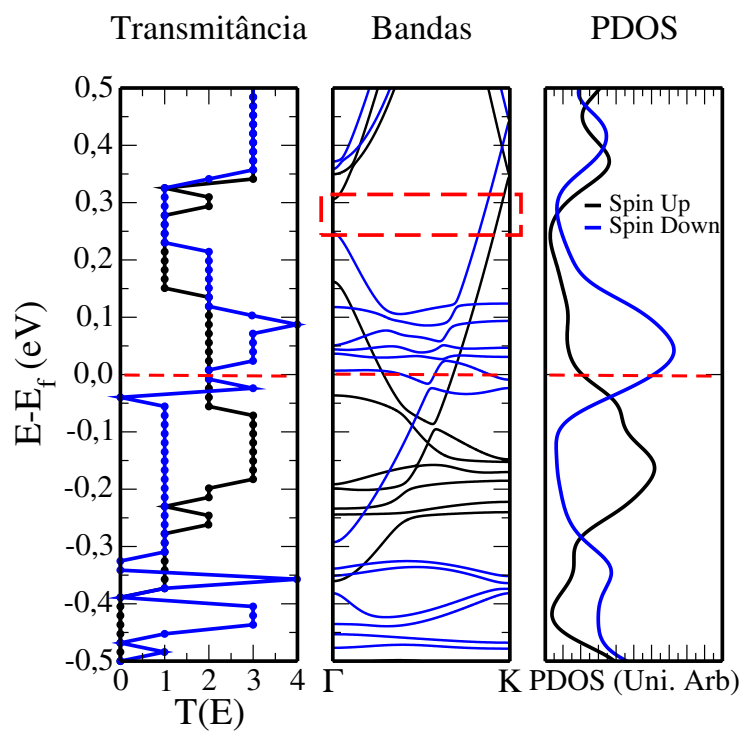

(b) Transmitância, bandas e PDOS do eletrodo.

Figura 3.5: (a) Sistema formado pela região central de comprimento $D$, região de buffer e os eletrodos; (b) transmitância, estrutura de bandas e a respectiva densidade de estados projetada nos átomos de carbono do eletrodo. O retângulo com a linha vermelha tracejada destaca uma região de menor densidade de estados, responsável por uma transmitância aproximadamente nula dos sistemas $S 1$ e $S 2$ nessa região do espectro de energia.

A transmitância dos sistemas $S 1$ e $S 2$ foi determinada e os resultados são apresentados na Figura 3.6(a) e Figura 3.6(b), respectivamente. Como a região central desses nanossistemas é semicondutora, é esperada uma transmitância nula para energias $E$ próximas ao nível de Fermi (dentro do gap de energia do nanotubo de carbono). Porém, é observada uma transmitância não nula no entorno do nível de Fermi desses sistemas. A hipótese é a de que estados os dos eletrodos se estendem pela região central contribuindo para a transmitância 
do sistema. Para mostrar isso, foram demonstradas graficamente as densidades de estados projetadas nos átomos de carbono de um anel ${ }^{1}$ do eletrodo e de um anel no centro geométrico do sistema representado na Figura 3.5(a). Conforme o gráfico da Figura 3.7(a), na região do gap (do nanotubo de carbono sem átomos de paládio) do espectro de energia existem estados mesmo no centro geométrico do sistema (região sem átomos de paládio). A densidade de estados projetada nos átomos de carbono nessa região física, no entanto, é menor em comparação com a região do eletrodo, indicando uma queda da influência dos estados do eletrodo nessa região.

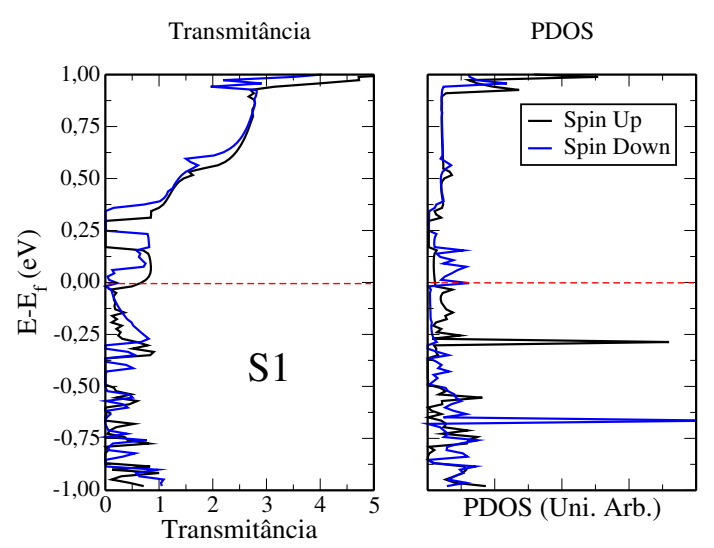

(a) Transmitância e densidade de estados projetada nos átomos de carbono do sistema $S 1$.

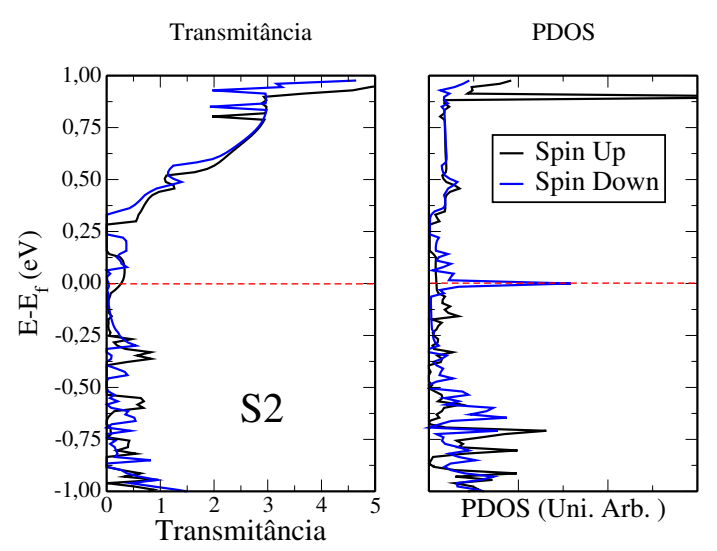

(b) Transmitância e densidade de estados projetada nos átomos de carbono do sistema $S 2$.

Figura 3.6: Transmitâncias e densidades de estados projetadas (PDOS) nos átomos de carbono dos sistemas (a)S1 e (b)S2.

O decaimento da densidade de estados projetada nos átomos de carbono com energias dentro da região do gap de energia do nanotubo de carbono ao longo do sistema $S 1$ na direção do seu centro geométrico é apresentado na Figura 3.7(b). Para a construção desse gráfico, foram consideradas as densidades de estados projetadas nos átomos de carbono dos vários aneis que compõem o sistema (tanto $S 1$ quanto $S 2$ ). A curva da densidade de estados projetada nos átomos de carbono em função da posição desses aneis foi determinada para três valores fixos de energia, estando eles dentro da região gap do nanotubo de carbono

\footnotetext{
${ }^{1}$ Um anel é formado por uma cadeia de 20 átomos de carbono de uma seção circular do nanotubo de carbono.
} 
puro (no entorno do nível de Fermi) ${ }^{1}$. No gráfico da Figura 3.7(b) é possível observar que a densidade de estados diminui na direção do centro geométrico, indicando uma menor influência dos estados dos eletrodos nessa região física do sistema.

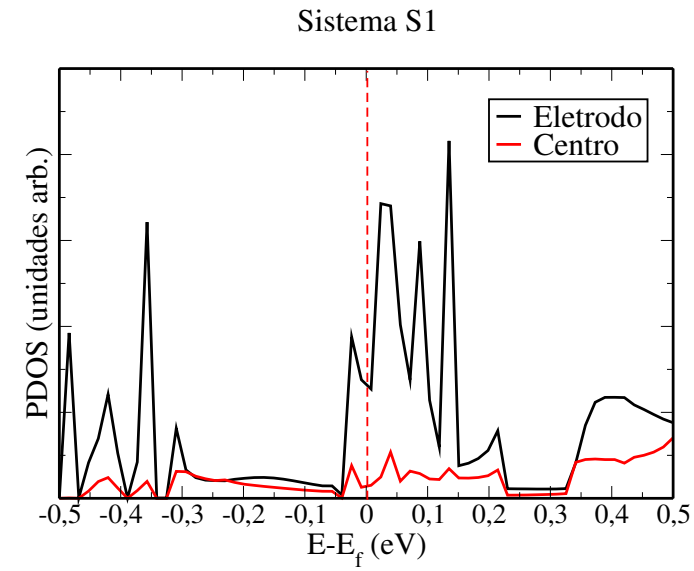

(a) PDOS do sistema $S 1$ para duas regiões distintias.

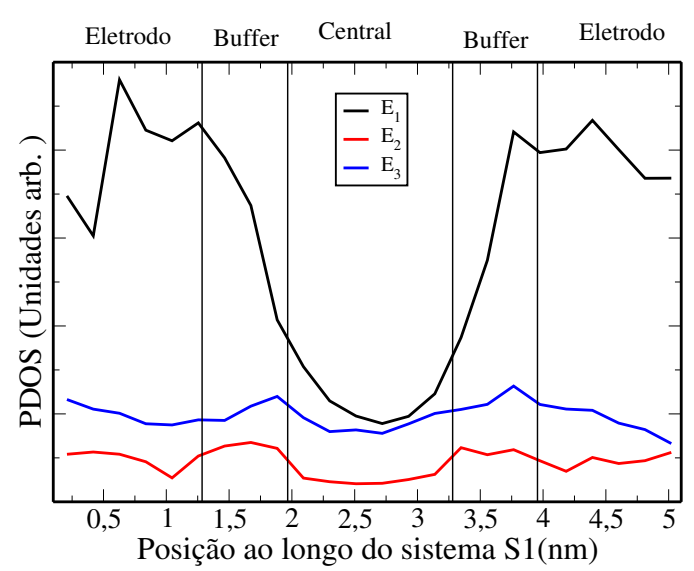

(b) Variação da PDOS ao longo do sistema $S 1$ para três valores fixos de energia.

Figura 3.7: (a) Comparação da densidade de estados projetadas (PDOS) nos átomos de carbono de um anel do eletrodo e do centro geométrico do sistema $S 1$; (b) variação da densidade de estados projetada nos átomos de carbono ao longo do sistema $S 1$ para três valores fixos de energias $\left(E_{1}, E_{2}\right.$ e $\left.E_{3}\right)$ dentro do gap de energia do nanotubo de carbono.

Embora exista uma transmitância finita no entorno do nível de Fermi no espectro de energia dos sistema $S 1$ e $S 2$, com o aumento do comprimento da região central há uma diminuição desse valor, conforme é mostrado no gráfico da Figura 3.8(a). Isso é explicado, em parte, ${ }^{2}$ pela menor influência dos estados dos eletrodos na região central do sistema $S 2$ em comparação com o sistema $S 1$. Para mostrar isso, foram determinadas as densidades de estados projetadas nos átomos de carbono de um anel do centro geométrico dos dois sistemas ( $S 1$ e $S 2$ ), sendo os resultados apresentados na Figura 3.8(a). Uma diminuição na densidade de estados do sistema $S 2(D=2,81 \mathrm{~nm})$ em comparação com o $S 1(D=1,61 \mathrm{~nm})$ pode ser observada neste gráfico, indicando uma menor influência dos estados dos eletrodos na região central dos nanossitemas. Com menor densidade dos estados dos eletrodos na

\footnotetext{
${ }^{1}$ A posição do gap de energia no entorno do nível de Fermi do nanotubo de carbono não é alterada significativamente pela dopagem por ela ser considerada pequena.

${ }^{2} \mathrm{O}$ aumento do comprimento $D$ implica numa maior região de espalhamento de portadores de carga, havendo também uma diminuição da transmitância.
} 
região central do sistema $S 2$ em comparação com o sistema $S 1$, é esperada uma menor contribuição desses estados na transmitância, explicando assim, em parte, a diferença entre as transmitâncias dos sistemas $S 1$ e $S 2$. É esperado que, com o aumento do comprimento $D$ da região central, haja uma diminuição significativa da influência dos estados do eletrodo na transmitância do sistema.

A intensidade da corrente elétrica — devido a um potencial de bias — foi determinada por meio da integração das transmitâncias conforme a equação (B.62) do Apêndice B. Nessa integral foi considerado que, para valores de bias de até $60 \mathrm{mV}$, a transmitância dos nanossistemas é constante, ou seja, não é função da diferença de potencial. Além disso, a integração das transmitâncias para a obtenção da intensidade da corrente elétrica foi realizada considerando baixas temperaturas, uma vez que os efeitos térmicos como, por exemplo, da interação elétron-fónon, não foram considerados na simulação do transporte eletrônico. Uma comparação entre as intensidades das correntes elétricas dos sistemas $S 1$ e $S 2$ sem campo elétrico de gate é apresentada na Figura 3.8(b). Essa figura mostra que a intensidade da corrente elétrica do sistema $S 1$ (linhas pontilhadas) é maior que a intensidade da corrente elétrica do sistema $S 2$ para uma mesma diferença de potencial de bias, podendo-se atribuir esse resultado à maior densidade de estados dos eletrodos na região central, contribuindo para a transmitânica do sistema, como destacado anteriormente. Os resultados obtidos até aqui mostram que há nos sistemas (tanto $S 1$ quanto $S 2$ ) uma corrente de intensidade finita quando o sistema é submetido a uma pequena diferença de potencial de bias, não havendo uma barreira de potencial. Isso pode ser compreendido pela influência dos estados dos eletrodos (com energias dentro do gap do nanotubo de carbono puro) na região do centro geométrico do sistema, como mostrado nesta seção. 


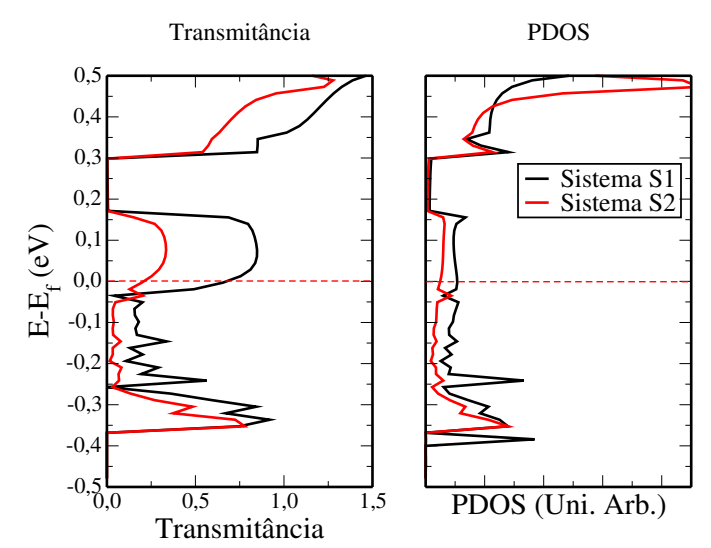

(a) Comparação das transmitâncias e PDOS dos sistemas $S 1$ e $S 2$.

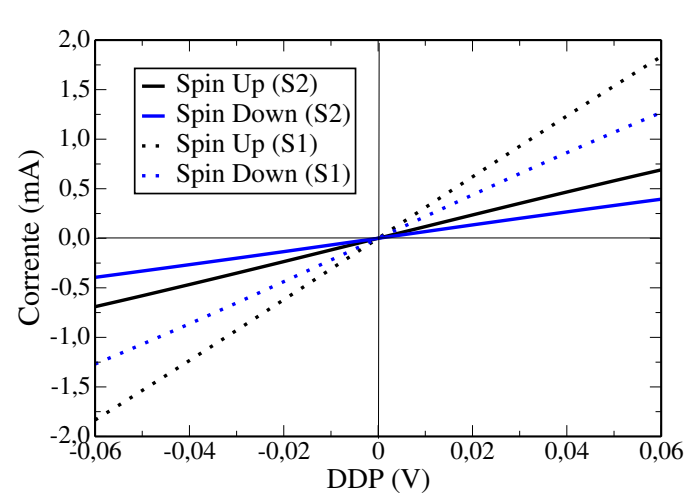

(b) Intensidade da corrente elétrica em função da diferença de potencial nos sistemas $S 1$ e $S 2$.

Figura 3.8: (a) Comparação das transmitâncias e da densidade de estados projetada nos átomos de carbono dos sistemas $S 1$ e $S 2$, considerando um único canal de spin; (b) comparação das intensidades das correntes elétricas dos sistemas $S 1$ e $S 2$.

Uma região de transmitância aproximadamente nula $\left(T(E) \sim 10^{-3}\right)$ entre 0,2 e $0,3 \mathrm{eV}$ do espectro de energia é encontrada na Figura 3.6(a) e na Figura 3.6(a). Isso pode ser explicado a partir da análise da região em destaque da estrutura de bandas do eletrodo na Figura 3.5(b), demarcada pela linha vermelha tracejada. Conforme destacado nessa figura, há uma região no espectro de energia em que não há estados do nanofio (bem como estados híbridos da ligação C-paládio) próximo ao ponto $\Gamma$ e que, portanto, não preenchem o gap de energia do nanotubo. Mas existem estados menos planos próximo ao ponto $K$ nessa região do espectro de energia. Considerando que a transmitância tanto do sistema $S 1$ quanto do $S 2$ é aproximadamente nula nessa região, conclui-se que esses estados (menos planos) contribuem menos para a transmitância. Ou seja, os estados provenientes do eletrodo que são menos planos possuem uma influência menor na região central, contribuindo menos para a transmitância dos sistemas, em comparação com outros estados do eletrodo. Esse resultado sugere que os diferentes estados provenientes dos eletrodos possuem influências distintas na transmitância. 


\subsection{O efeito do campo elétrico de gate.}

\subsubsection{Variação do gap de energia do nanotubo de carbono pristino.}

A modulação do gap de energia dos nanotubos de carbono semicondutores em razão do campo elétrico de gate é discutida em alguns trabalhos teóricos $(3,66,67,68,69,70)$. A curva do gap de energia $\left(E_{g}\right)$ do nanotubo de carbono $(10,0)$ com o módulo do campo elétrico de gate $(|\vec{E}|)$ é apresentada na Figura 3.9. De acordo com os resultados do presente trablalho, um campo elétrico de gate de módulo $\sim 1,63 \mathrm{~V} /$ Å é necessário para fechar o gap de energia desse nanotubo.

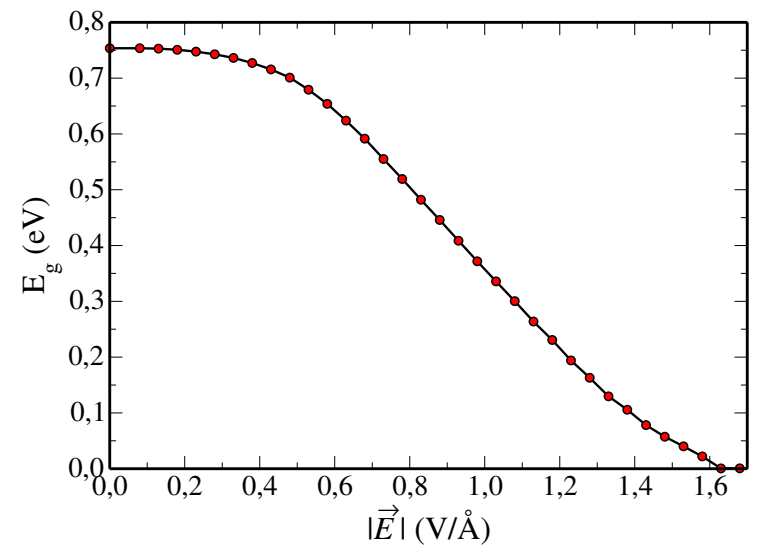

Figura 3.9: Curva $E_{g} \times|\vec{E}|$ do nanotubo de carbono $(10,0)$.

A explicação para a variação do gap de energia dos nanotubos de carbono é dada por Zheng et al.(71). Segundo os autores, estados da banda de valência são deslocados no sentido oposto ao do campo elétrico. Como resultado, os estados da banda de valência e de condução ficam confinados em lados opostos do nanotubo de carbono, porém ficam mais próximos em energia.

Variações na intensidade da corrente elétrica entre a fonte e o dreno podem ser obtidas quando o nanotubo de carbono é submetido a um campo elétrico de gate, devido à variação do seu gap de energia ${ }^{1}$. Para investigar isso, será considerado o efeito do campo elétrico nas

\footnotetext{
${ }^{1}$ Variações na condutividade são conseguidas também pelo deslocamento do nível de Fermi do sistema devido a um campo elétrico de gate de comprimento finito (2). Isso não poderá ser observado no presente trabalho, pois o campo elétrico utilizado possui um gate de comprimento infinito.
} 
simulações de transporte eletrônico.

\subsubsection{O efeito do campo elétrico de gate no transporte eletrônico}

Foram realizadas simulações computacionais de transmporte eletrônico com os sistemas $S 1$ e $S 2$ submetidos a um campo elétrico de gate de módulo $16,3 \mathrm{~V} / \mathrm{nm}$.

Há uma variação mais significativa da intensidade da corrente elétrica (devido ao campo elétrico de gate) no sistema $S 2$ em comparação com o sistema $S 1$ - para uma mesma diferença de potencial de bias — como pode ser observado na Figura 3.10(a) e na Figura 3.10(b). Isso é explicado pela menor influência dos estados dos eletrodos na região central do sistema $S 2$ em comparação com o sistema $S 1$, como destacado na Seção 3.3.

Sistema S2

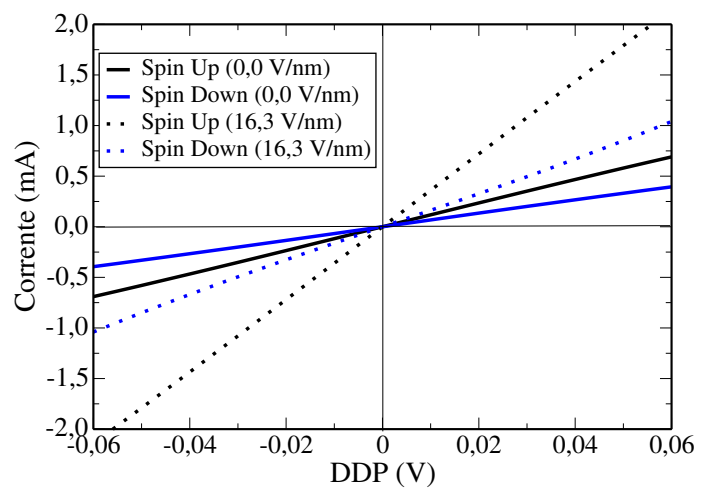

(a) Curva da intensidade da corrente elétrica do sistema $S 2$ em função da DDP.
Sistema S1

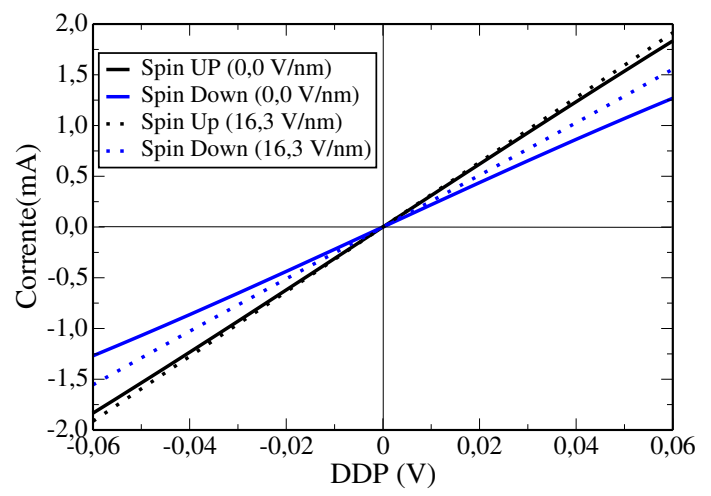

(b) Curva da intensidade da corrente elétrica do sistema $S 1$ em função da DDP.

Figura 3.10: Variações maiores na intensidade da corrente devido ao campo elétrico de gate são observadas no sistema $S 2$ (a) se comparadas ao sistema $S 1$ (b) para uma mesma diferença de potencial (DDP).

A variação na intensidade das correntes elétricas dos sistemas $S 1$ e $S 2$ com o campo elétrico de gate, sugere que este nanossistema possui potencial para aplicações como transistor de efeito de campo. Relações $I_{o n} / I_{o f f}$ entre a intensidade da corrente elétrica do sistema foram determinadas para o sistema $S 1\left(1 \times 10^{0}\right)$ e o sistema $S 2\left(3 \times 10^{0}\right)$. Os valores de $I_{o n} / I_{\text {off }}$ mostram que esses nanossistemas possuem potencial em aplicações como transis- 
tores de efeito de campo não-lógicos. No entanto, relações $I_{o n} / I_{o f f}$ maiores poderão ser conseguidas aumentando o comprimento $D$ do nanossistema para diminuir a influência dos estados dos eletrodos, como sugerem os resultados aqui obtidos.

\subsection{Polarização da corrente elétrica.}

A intensidade da corrente elétrica é maior para o canal de spin up se comparado ao canal de spin down, conforme pode ser observado na Figura 3.10(b). Isso se deve a uma maior contribuição dos estados de spin up em comparação com os estados spin down para a transmitância dos sistemas. Portanto, esses sistemas apresentam uma polarização da corrente elétrica $C P$ :

$$
C P=\frac{I_{\uparrow}-I_{\downarrow}}{I_{\uparrow}+I_{\downarrow}},
$$

onde $I_{\uparrow}$ e $I_{\downarrow}$ são as intensidades das correntes elétricas dos canais de spin up e spin down, respectivamente. Os resultados obtidos aqui para a polarização da corrente são: $17 \%(|\vec{E}|=$ $0,0 \mathrm{~V} / \mathrm{nm})$ e $11 \%(|\vec{E}|=16,3 \mathrm{~V} / \mathrm{nm})$ para o sistema $S 1 ; 27 \%(|\vec{E}|=0,0 \mathrm{~V} / \mathrm{nm})$ e $37 \%(|\vec{E}|=$ $16,3 \mathrm{~V} / \mathrm{nm}$ ) para o sistema $S 2$. Os valores de $C P$ desses sistemas são menores do que, por exemplo, os valores da polarização da corrente elétrica de metais com momento magnético resultante não nulo, como o níquel (46\%), o ferro (45\%) e o cobalto (42\%), sendo esses valores obtidos experimentalmente por Jr et al.(72). 
$\Gamma_{\text {Capítulo }}$

\section{A INFLUÊNCIA DOS SUBSTRATOS

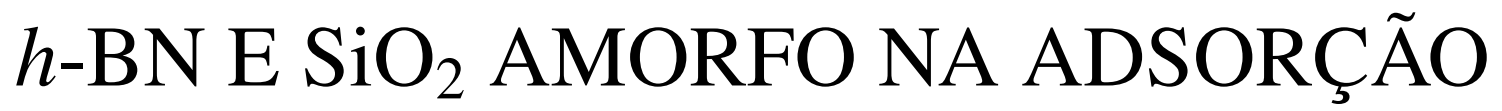 DO $\mathrm{H}_{2}$ PELO GRAFENO.}

O hidrogênio molecular $\left(\mathrm{H}_{2}\right)$ possui destaque como combustível para automóveis por ser considerado pouco poluente em comparação com os combustíveis fósseis. Porém, há problemas quanto à segurança na sua produção e estocagem, pois o gás $\mathrm{H}_{2}$ é potencialmente explosivo em concentrações volumétricas acima de $4 \%$ na atmosfera $(73,74)$. Assim, a segurança é uma preocupação quando o assunto é a sua produção e estocagem.

Sensores de $\mathrm{H}_{2}$ à base de nanofios de paládio (Pd) já são produzidos (75). No entanto, o custo do paládio aumentou drasticamente nos últimos anos (76), restringindo a sua larga utilização. Sensores à base de grafeno poderiam ser uma alternativa barata aos atuais sensores à base de paládio, levando-se em conta as propriedades do grafeno para a detecção de moléculas, como a alta sensibilidade (11). Porém, as propriedades eletrônicas do grafeno pristino são pouco influenciadas com a adsorção do $\mathrm{H}_{2}$ em condições normais de temperatura e pressão (77), sendo isso atribuído à baixa polarizabilidade e ao caráter de camada fechada da molécula. Assim, a detecção do $\mathrm{H}_{2}$ por meio de sensores à base de grafeno é atualmente um desafio. 
As propriedades eletrônicas do grafeno pristino são também pouco influenciadas com a adsorção do gás oxigênio $\left(\mathrm{O}_{2}\right)$ em condições normais de temperatura e pressão (12). No entanto, estudos experimentais (13) realizados com o grafeno depositado no substrato óxido de silício $\left(\mathrm{SiO}_{2}\right)$ mostram ser possível a detecção do gás $\mathrm{O}_{2}$ nessas condições. A hipótese dos autores é que há uma influência do substrato na transferência de carga entre a molécula e o restante do sistema. A transferência de carga é observada indiretamente por meio de medidas que indicam o deslocamento do ponto de neutralidade de carga (ver Capítulo 2). Portanto, há questões que precisam ser mais bem compreendidas sobre a influência dos substratos na adsorção dos gases no grafeno. Dentre elas, a influência dos substratos nas energias de adsorção (e assim, nas propriedades termodinâmicas do sistema) e também na transferência de carga entre a molécula do gás e o grafeno.

No presente trabalho foram determinadas grandezas físicas como a energia de adsorção e a quantidade de carga transferida para investigar a influência dos substratos óxido de Silício $\left(\mathrm{SiO}_{2}\right)$ amorfo e o nitreto de Boro hexagonal ( $h$-BN) na adsorção do $\mathrm{H}_{2}$ pelo grafeno. $\mathrm{O}$ objetivo do trabalho é responder o quanto essas grandezas físicas são influenciadas pela adsorção da molécula $\mathrm{H}_{2}$ pelo grafeno depositado nesses substratos em comparação com o grafeno suspenso. Esse estudo pode levar a novas possibilidades, contribuindo para o desenvolvimento de futuros sensores de $\mathrm{H}_{2}$ à base de grafeno.

\subsection{Metodologia.}

Foram utilizados pseudopotenciais de norma conservada (50) para descrever a interação entre os caroços iônicos e os elétrons de valência, sendo esses elétrons de valência representados por um conjunto de base tipo duplo- $\zeta$ com mesh cutoff de 300Ry, conforme implementado no código SIESTA(49). Foi utilizado um número de pontos $k$ para representar a zona de Brillouin, de forma que a convergência na energia total fosse menor ou igual a $3 m e V$ por célula unitária, sempre utilizando a amostragem de Monkhorst e Pack(51). Na 
otimização das geometrias do sistema foi adotado o critério de que as forças resultantes sobre os átomos são menores que $0,01 \mathrm{eV} / \AA$.

Os cálculos $a b$ initio foram realizados utilizando o funcional para a energia de troca e correlação LDA. Conforme Henwood e Carey(78), esse funcional tem a tendência de superestimar a energia de ligação quando comparada com resultados experimentais $(79,80)$. Já o funcional para a energia de troca e correlação GGA tem a tendência de subestimar as energias de ligação $(80,81)$. A correção de Grimme(82) na energia total do sistema pode ser inserida para representar as interações de van der Waals. No entanto, o funcional LDA fornece bons resultados com boa concordância com os dados experimentais em determinadas situações em que as interações tipo van der Waals são relevantes (83), sendo isso explicado pelo cancelamento mútuo entre erros nas aproximações de troca e correlação $(81,84,85)$. A energia de ligação superestimada pelo funcional para as energias de troca e correlação LDA $(86,87)$ é compensada pela não correção das energias devido à interação de van der Waals (88). Outros autores como, por exemplo, Tozzini e Pellegrini(89) utilizam também o funcional para a energia de troca e correlação LDA em sistemas semelhantes, sendo a sua utilização aplicável ao sistema investigado no presente trabalho.

\subsection{A adsorção do $\mathrm{H}_{2}$ pelo grafeno suspenso.}

A adsorção da molécula de $\mathrm{H}_{2}$ pelo grafeno suspenso (sem substrato) pode ocorrer em diversos sítios. Para verificar a existência de um possível sítio de mais baixa energia de adsorção, foram aqui analisadas onze configurações diferentes da molécula sobre o grafeno, sendo elas consideradas também por Henwood e Carey(78) para moléculas diatômicas. As coordenadas da molécula $\mathrm{H}_{2}$ foram otimizadas em cada uma das onze configurações separadamente, mantendo as coordenadas do grafeno fixas. Após a otimização da geometria, foi determinada para cada uma das onze configurações a energia de adsorção:

$$
E_{a d}=E_{H_{2} \text { adsorvido }}-E_{H_{2} \text { afastado }},
$$


onde $E_{H_{2} \text { adsorvido }}$ é a energia do sistema com o $\mathrm{H}_{2}$ adsorvido no grafeno, e $E_{H_{2} \text { afastado }}$ é a energia do sistema com o $\mathrm{H}_{2}$ afastado de $20 \AA$ da superfície do grafeno ${ }^{1}$. O sítio na qual $E_{a d}$ é menor (mais negativa) é conhecido como hollow, em consonância com os resultados de Ghosh et al.(90). Nesse sítio, a molécula de $\mathrm{H}_{2}$ está localizada acima do centro do hexágono do grafeno ${ }^{2}$. A orientação da molécula $\mathrm{H}_{2}$ pode ser paralela ou perpendicular à superfície do grafeno nesse sítio, sendo que a orientação perpendicular resulta na menor $E_{a d}$, de acordo com os resultados obtidos aqui. A energia de adsorção da molécula $\mathrm{H}_{2}$ nessa configuração sobre o grafeno é de $E_{a d}=-0,12 \mathrm{eV}$. Estudos experimentais mostraram que a adsorção do $\mathrm{H}_{2}$ pode ocorrer somente à temperatura criogênica (91) ou pressões maiores que 1 atm $(92,93)$ para assegurar o armazenamento com estabilidade. Portanto, energias de adsorção menores (mais negativas) são essenciais para manter $\mathrm{o}_{2}$ adsorvido pelo grafeno em condições normais de temperatura e pressão.

A estrutura das bandas de energia do grafeno não é modificada próximo ao nível de Fermi $E_{f}$ (onde ocorrem os fenômenos de transporte eletrônico) pela adsorção do $\mathrm{H}_{2}$, como pode ser observado na Figura 4.1. Isso ocorre porque o $\mathrm{H}_{2}$ apresenta estados com níveis profundos de energia em comparação com o nível de Fermi do sistema. Além disso, não há ligação química da molécula $\mathrm{H}_{2}$ com o grafeno. Segundo Ni et al.(94), ligações químicas introduzem níveis ressonantes próximo ao nível de Fermi do grafeno, não sendo isso observado no presente trabalho.

Os estados do $\mathrm{H}_{2}$ estão à $\sim 5 \mathrm{eV}$ abaixo do nível de Fermi do sistema. Há uma mistura dos estados $\sigma$ da molécula $\mathrm{H}_{2}$ com os estados hibridos do grafeno nessa região do espectro de energia, conforme destacado por Henwood e Carey(78). Isso pode ser confirmado pelo alargamento da densidade de estados projetado nos átomos do $\mathrm{H}_{2}$, como apresentado na Figura 4.1.

\footnotetext{
${ }^{1}$ Com essa distância de separação, os efeitos na energia total do sistema, devido às interações entre o grafeno e o $\mathrm{H}_{2}$, podem ser desprezadas para as finalidades desse trabalho.

${ }^{2}$ Com a molécula $\mathrm{H}_{2}$ separada de $2,34 \AA$ determinada a partir do átomo de $\mathrm{H}$ mais próximo do grafeno.
} 


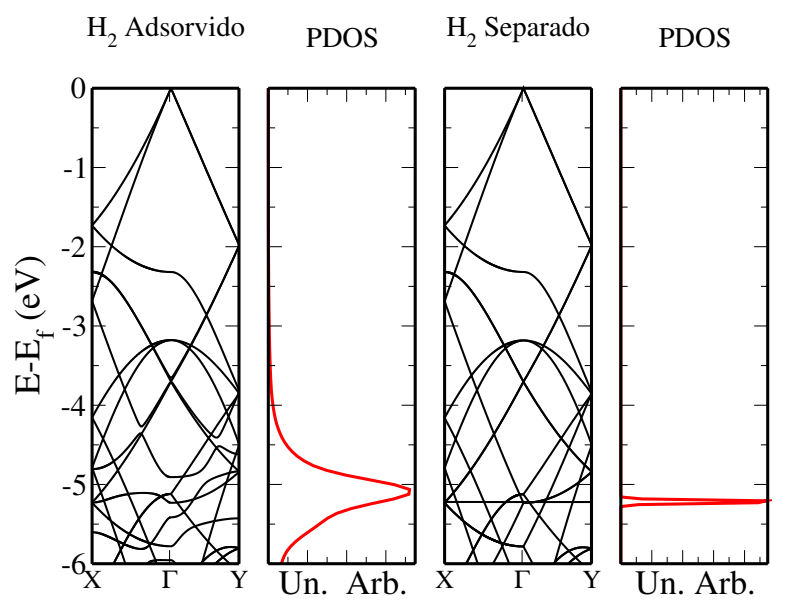

Figura 4.1: Comparação da estrutura de bandas de energia e a respectiva densidade de estados projetada nos átomos de $\mathrm{H}$ do sistema com o $\mathrm{H}_{2}$ adsorvido e afastado por uma distância de $20 \AA$ do grafeno.

A quantidade de carga transferida entre a molécula $\mathrm{H}_{2}$ e o grafeno é aproximadamente nula $\left(Q_{T}=0,007 e\right)$. Este resultado foi obtido por meio da integração da densidade de estados projetada nos átomos de carbono. A diferença entre a carga total de valência dos átomos de carbono (determinada pela integração da densidade de estados projetada nos átomos de carbono de $-\infty$ até $E_{f}$ ) com o $\mathrm{H}_{2}$ adsorvido e afastado do grafeno resulta na quantidade de carga transferida $\left(Q_{T}\right)$ entre a molécula e o grafeno, ou seja:

$$
Q_{T}=Q_{H_{2} \text { adsorvido }}-Q_{H_{2} \text { afastado }}
$$

Os resultados obtidos aqui mostram que as propridades eletrônicas do grafeno não são alteradas significativametente com a adsorção do $\mathrm{H}_{2}$. A influência dos susbstratos na adsorção do $\mathrm{H}_{2}$ pelo grafeno será investigada na próxima seção.

\subsection{Grafeno depositado no $\mathrm{SiO}_{2}$ amorfo e $h$-BN.}

\subsubsection{Caracterização do $\mathrm{SiO}_{2}$ amorfo como substrato para o grafeno.}

$\mathrm{O} \mathrm{SiO}_{2}$ amorfo é amplamente utilizado como substrato para a deposição do grafeno na fabricação de dispositivos eletrônicos e medidas de grandezas físicas $(95,96) . \mathrm{O} \mathrm{SiO}_{2}$ 
amorfo utilizado no presente trabalho e representado na Figura 4.2(a) possui as mesmas coordenadas do sistema utilizado por Miwa et al.(97), sendo essa estrutura gerada por meio de uma dinâmica molecular ab initio via o esquema melt-and-quench(98).

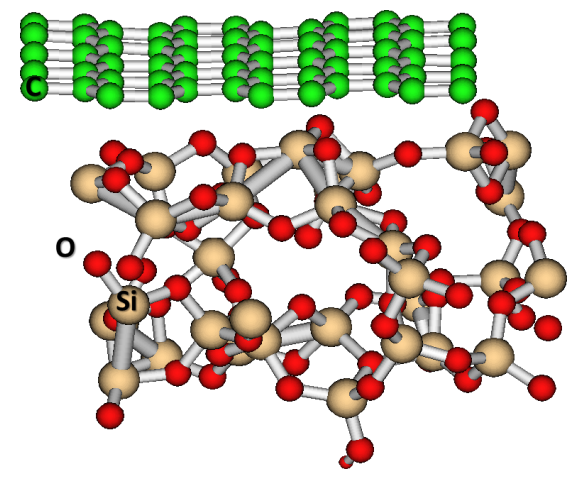

(a) Grafeno depositado no $\mathrm{SiO}_{2}$ amorfo.

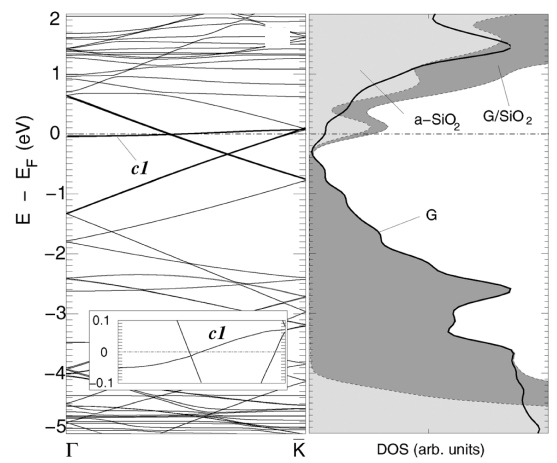

(b) Estrutura de bandas e DOS.

Figura 4.2: (a) Representação pictórica do sistema; (b) estrutura de bandas do sistema. No lado direito dessa figura está representada graficamente a densidade de estados (DOS) dos sistemas: Grafeno $(\mathrm{G})$, substrato $\mathrm{SiO}_{2}$ amorfo $\left(\mathrm{a}-\mathrm{SiO}_{2}\right)$ e grafeno depositado no $\mathrm{SiO}_{2}$ amorfo $\left(\mathrm{G}_{\mathrm{SiO}}\right)$. Fonte: Miwa et al.(97), 2011.

As bandas lineares no entorno do ponto de Dirac — conforme apresentado na Figura 4.2(b) — indicam que há um fraco acoplamento do grafeno com o substrato. Porém, há um deslocamento do nível de Fermi em relação ao ponto de Dirac, indicando uma transferência de carga do substrato para o grafeno (dopagem tipo $n$ ). Segundo Miwa et al.(97), o caráter dopado do grafeno se deve a introdução de um nível parcialmente ocupado próximo ao ponto de Dirac, proveniente de um átomo de oxigênio com tripla coordenação no substrato. A carga transferida do substrato para o grafeno está distribuída de forma não homogênea na sua superfície, conforme Miwa et al.(97). Assim, esperam-se diferenças na energia de adsorção e na transferência de carga entre o $\mathrm{H}_{2}$ e o restante do sistema devido à interação da molécula com a carga adicional presente no grafeno depositado no $\mathrm{SiO}_{2}$ amorfo, em comparação com o grafeno suspenso. Esta hipótese será investigada na Seção

\subsection{3.}




\subsubsection{Caracterização do $h$-BN como substrato para o grafeno.}

O $h$-BN é outro substrato amplamente utilizado para a deposição do grafeno na construção de dispositivos eletrônicos (99). A mobilidade dos portadores de carga no grafeno depositado nesse substrato é maior em comparação com o grafeno depositado no substrato $\mathrm{SiO}_{2}$ amorfo (100).

$\mathrm{O} h$-BN é um isolante com um gap de energia de $\sim 6,0 \mathrm{eV}$, obtido experimentalmente por Watanabe et al.(101). A rede do $h$-BN é similar a do grafeno, porém ela apresenta dois átomos de elementos distintos ocupando as diferentes subredes $A$ e $B$. Segundo os trabalhos de Padilha et al.(102), a configuração do grafeno sobre o $h$-BN de mais baixa energia é a bernal como mostrada na Figura 4.3(a), sendo esta utilizada nas simulações aqui realizadas. Camadas subsequentes de $h$-BN são empilhadas de modo que átomos de B e N ficam dispostos uns sobre os outros de modo alternado, separados por uma distância de 3, $18 \AA ̊$. O grafeno depositado no $h$-BN possui forma planar e distribuição aproximadamente homogênea de carga ao longo do sistema, sendo isso demonstrado experimentalmente (100). As duas subredes do grafeno depositado no $h$-BN tornam-se inequivalentes como resultado da interação com os átomos do substrato. Isso explica a abertura de um gap de energia de aproximadamente $53 \mathrm{meV}$, de acordo com estudos teóricos de Giovannetti et al.(103). A abertura do gap de energia do grafeno depositado no $h$-BN é destacada na Figura 4.3(b).

Existe uma diferença entre os parâmetros de rede do grafeno e do $h$-BN devido à diferença entre o comprimento das ligações químicas dos seus elementos. Segundo Sachs et al.(104), essa diferença $(\sim 2 \%)$ pode ser ignorada em uma primeira aproximação nas simulações computacionais, havendo uma boa aproximação com os resultados experimentais(99). 


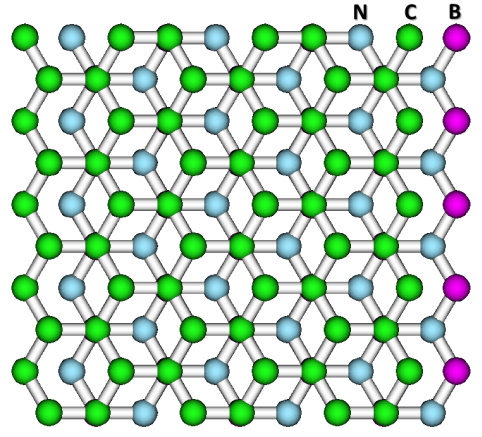

(a) Empilhamento bernal.

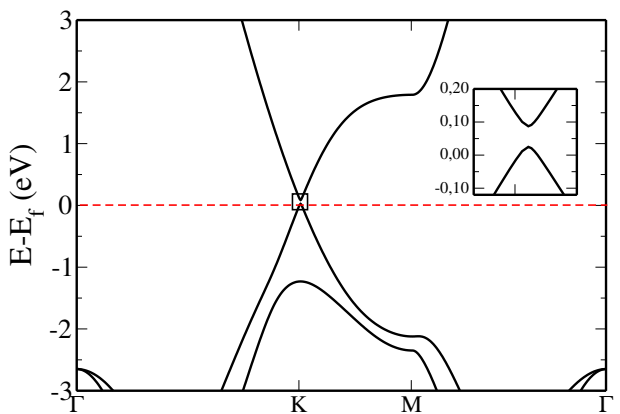

(b) Bandas de energia.

Figura 4.3: (a) Grafeno depositado no substrato $h$-BN com empilhamento bernal; (b) estrutura de bandas de energia do sistema, destacando a abertura de um gap de energia devido à interação dos átomos de carbono com os do substrato.

O caráter aproximadamente linear das bandas de energia do grafeno no entorno do ponto de Dirac é preservado, ${ }^{1}$ sendo esta estrutura comparável ao grafeno suspenso, como pode ser observado no gráfico de bandas de energia na Figura 4.3(b).

\subsection{3 $\mathrm{H}_{2}$ adorvido pelo grafeno depositado no $\mathrm{SiO}_{2}$ amorfo e $h$-BN.}

Foram inicialmente determinadas as energias de adsorção do $\mathrm{H}_{2}$ adsorvido pelo grafeno depositado em ambos os substratos (configuração denominada sobre) e também na região intersticial (entre o grafeno e o substrato), sendo essa configuração denominada entre. A energia de adsorção do $\mathrm{H}_{2}$ adsorvido no sítio hollow na configuração sobre do sistema formado pelo grafeno depositado no $\mathrm{SiO}_{2}$ amorfo foi determinada após a otimização das geometrias do $\mathrm{H}_{2}$, com as coordenadas do restante do sistema sendo mantidas fixas. Foram considerados nesse estudo todos os sítios hollow da célula unitária do sistema apresentado na Figura 4.2(a). Variações de até 5,5\% são observadas nos valores de $E_{a d}$, sendo esta variação explicada pela distribuição não homogênea de carga no grafeno depositado nesse substrato.

A energia de adsorção foi também determinada com o $\mathrm{H}_{2}$ adsorvido pelo grafeno de-

\footnotetext{
${ }^{1}$ Entretanto, existe um gap de energia de $53 \mathrm{meV}$.
} 
positado no $h$-BN. A configuração de mais baixa energia de adsorção do $\mathrm{H}_{2}$ nesse sistema é a mesma do grafeno suspenso. Foram consideradas mais camadas de $h$-BN no substrato (1 $h$-BN, $2 h$-BN e $4 h$-BN) para analisar a variação da energia de adsorção com o $\mathrm{H}_{2}$ adsorvido pelo grafeno na configuração sobre. Os resultados apresentados na Figura 4.4(a) mostram que as energias de adsorção do $\mathrm{H}_{2}$ adsorvido pelo grafeno suspenso e depositado no substrato $h$-BN (independente do número de camadas, dentre as aqui consideradas) são comparáveis.

Energias de adsorção foram determinadas também com a molécula $\mathrm{H}_{2}$ depositada na região intersticial (configuração entre) ${ }^{1}$. As coordenadas do $\mathrm{H}_{2}$ foram otimizadas com as coordenadas do restante do sistema sendo mantidas fixas. A energia de adsorção foi determinada para cada uma das configurações. A análise dos resultados mostrou que existem regiões entre o $\mathrm{SiO}_{2}$ amorfo e o grafeno em que a adsorção do $\mathrm{H}_{2}$ é energeticamente favorável $\left(E_{a d}<0\right)^{2}$. Isso é explicado pela irregularidade na estrutura física do $\mathrm{SiO}_{2}$ amorfo, apresentando regiões com influência elástica desprezível. Tais regiões não são observadas no sistema formado pelo grafeno depositado no $h$-BN.

No diagrama da Figura 4.4(a) são apresentados os valores de $E_{a d}$ da molécula $\mathrm{H}_{2}$ adsorvida pelos sistemas aqui analisados ${ }^{3}$. Conforme a Figura 4.4(a), energias de adsorção do $\mathrm{H}_{2}$ adsorvido pelo grafeno suspenso ou depositado nos substratos são passíveis de comparação. Porém, o valor de $E_{a d}$ com o $\mathrm{H}_{2}$ adsorvido na região intersticial (entre o grafeno e o $\mathrm{SiO}_{2}$ amorfo) é três vezes menor em comparação com a adsorção do $\mathrm{H}_{2}$ no grafeno suspenso, mostrando uma influência significativa do substrato na adsorção do $\mathrm{H}_{2}$ nessa região.

$\mathrm{O}$ substrato $\mathrm{SiO}_{2}$ amorfo possui também uma influência significativa na quantidade de carga transferida $\left(Q_{T}\right)$ entre a molécula $\mathrm{H}_{2}$ e o restante do sistema, como pode ser observado

\footnotetext{
${ }^{1}$ Foram considerados os mesmos sítios da configuração entre, porém com a molécula em uma altura intermediária entre o grafeno e o substrato antes da otimização das geometrias.

${ }^{2}$ Existem também regiões nesse sistema para as quais a adsorção do $\mathrm{H}_{2}$ não é energeticamente favorável $\left(E_{a d}>0\right)$. Os valores de $E_{a d}$ das regiões energeticamente favoráveis são passíveis de comparação.

${ }^{3}$ No caso da molécula $\mathrm{H}_{2}$ adsorvido na região intersticial (entre o grafeno e o substrato $\mathrm{SiO}_{2}$ amorfo), foi escolhida uma dentre as configurações energeticamente favoráveis, uma vez que os valores de energia de adsorção são passíveis de comparação.
} 
no diagrama da Figura 4.4(b). A determinação de $Q_{T}$ foi realizada por meio da integração da densidade de estados projetada, considerando projeções tanto nos átomos do grafeno, quanto nos átomos do substrato, ou seja:

$$
Q_{T}=\left(Q_{H_{2} \text { adsorvido }}-Q_{H_{2} \text { afastado }}\right)_{\text {substrato }}+\left(Q_{H_{2} \text { adsorvido }}-Q_{H_{2} \text { afastado }}\right)_{\text {grafeno }} .
$$

De acordo com a Figura 4.4(b), a adsorção do $\mathrm{H}_{2}$ nos sistemas formados pelo grafeno depositado nos substratos resulta em um $Q_{T}$ maior em comparação com o grafeno suspenso. A adsorção da molécula $\mathrm{H}_{2}$ na região intersticial (entre o grafeno e o $\mathrm{SiO}_{2}$ ) resulta em um $Q_{T}$ de uma ordem de grandeza maior em comparação com a adsorção do $\mathrm{H}_{2}$ pelo grafeno suspenso $^{1}$. De acordo com os resultados obtidos pela equação (4.3.3), a quantidade de carga transferida da molécula para o restante do sistema é distribuida na seguinte proporção: $55 \%$ para o grafeno e $45 \%$ para o substrato. Ou seja, carga é transferida para o grafeno mesmo com a adsorção do $\mathrm{H}_{2}$ na região intersticial.

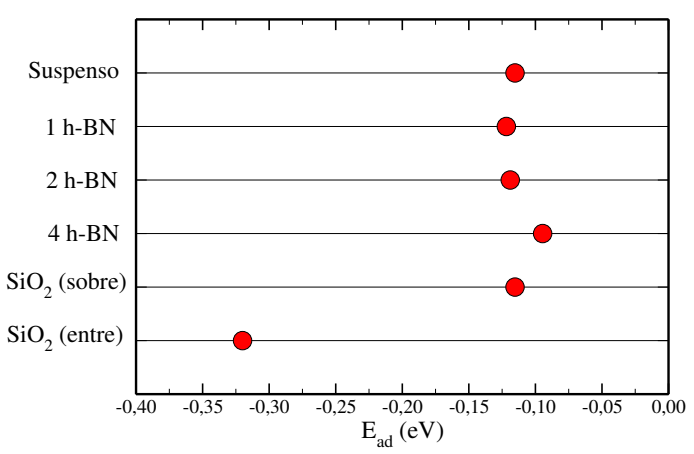

(a) Energias de adsorção.

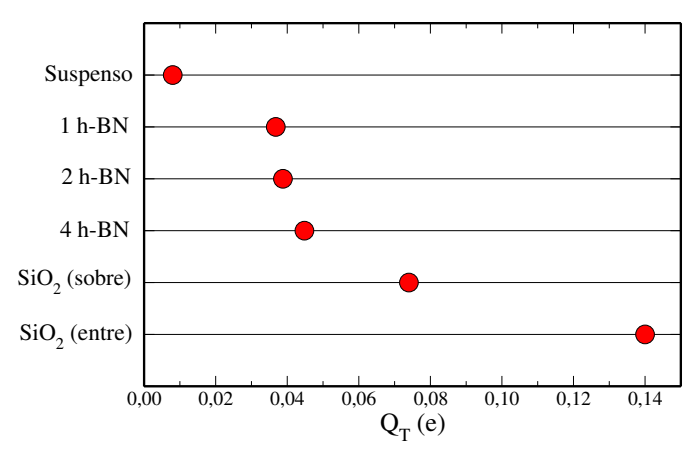

(b) Transferência de carga.

Figura 4.4: (a) Diagrama apresentando as energias de adsorção e quantidade de carga transferida (b) devido à adsorção da molécula de $\mathrm{H}_{2}$ nos sistemas analisados no presente trabalho.

A carga transferida da molécula $\mathrm{H}_{2}$ para o restante do sistema (devido a sua adsorção na região intersticial) resulta em um deslocamento do ponto de Dirac em relação ao nível de Fermi. Para mostrar isso, foram demonstradas graficamente — na mesma figura — as bandas de energia do sistema com a molécula $\mathrm{H}_{2}$ adsorvida (entre o grafeno e o $\mathrm{SiO}_{2}$ ) e

\footnotetext{
${ }^{1}$ Essa quantidade de carga representa uma dopagem na ordem de $10^{12} \mathrm{e} / \mathrm{cm}^{2}$.
} 


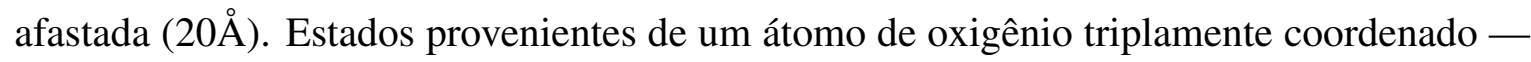
destacos em $C 1$ na Figura 4.2(b) - foram utilizados como referência com a justificativa de que a sua energia não varia significativamente com a adsorção da molécula, pois esse átomo de oxigênio está significativamente afastado da região de adsorção (ver Miwa et al.(97) ${ }^{1}$. Conforme a Figura 4.5, há um deslocamento do cone de Dirac de 8, $0 m e V$ devido à adsorção da molécula $\mathrm{H}_{2}$ na região intersticial. Este resultado sugere que a adsorção da molécula $\mathrm{H}_{2}$ nessa região pode resultar em um deslocamento do ponto de neutralidade de carga, conforme destacado no Capítulo 2.

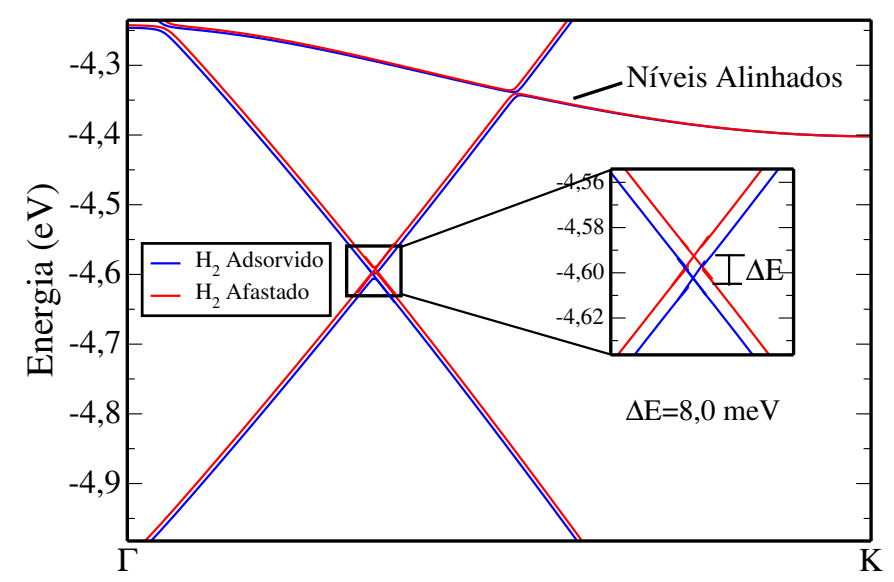

Figura 4.5: Deslocamento do ponto de Dirac com a adsorção do $\mathrm{H}_{2}$ na região intersticial do sistema formado pelo grafeno depositado no $\mathrm{SiO}_{2}$ amorfo.

A maior quantidade de carga transferida com a adsorção do $\mathrm{H}_{2}$ na região intersticial (entre o grafeno e o $\mathrm{SiO}_{2}$ amorfo), em comparação com o grafeno suspenso, pode ser devido a uma propriedade do $\mathrm{SiO}_{2}$ amorfo ou do sistema (grafeno+substrato). Para investigar isso, foi determinado $E_{a d}$ e $Q_{T}$ com a molécula adsorvida no $\mathrm{SiO}_{2}$ amorfo. Foi utilizada a mesma geometria do sistema formado pela molécula $\mathrm{H}_{2}$ adsorvida na região intersticial, porém sem os átomos de Cabono. A energia de adsorção obtida foi $E_{a d}=-0,24 \mathrm{eV}(\sim 1 / 3$ menor que a energia de adsorção da molécula $\mathrm{H}_{2}$ adsorvida no sistema com grafeno). Este resultado mostra que a molécula adsorve preferencialmente na região intersticial devido as propriedades do $\mathrm{SiO}_{2}$ amorfo e não do sistema (grafeno depositado no $\mathrm{SiO}_{2}$ amorfo). Já

\footnotetext{
${ }^{1}$ Também foi utilizado o nível de energia de uma molécula de $\mathrm{H}_{2}$ adicional — afastada da região de adsorção - como referência nesse estudo. Os dois resultados são comparáveis em termos absolutos.
} 
a quantidade de carga transferida da molécula $\mathrm{H}_{2}$ para o $\mathrm{SiO}_{2}$ amorfo é aproximadamente nula $(0,002 e)$. Esses dois resultados sugerem que: 1) não existe uma relação direta entre a energia de adsorção e a quantidade de carga transferida; 2) o grafeno depositado no $\mathrm{SiO}_{2}$ amorfo possui uma influência significativa na transferência de carga entre a molécula $\mathrm{H}_{2} \mathrm{e}$ o restante do sistema. No entanto, mais estudos são necessários para compreender melhor a influência do grafeno no processo de transferência de carga entre a molécula e o restante do sistema.

\subsection{A influência do campo elétrico.}

Na determinação do ponto de neutralidade de carga, o sistema é submetido a um campo elétrico de gate (na direção perpendicular à superfície do grafeno), conforme destacado na Seção 2.3.2. Nesta seção será analisada a influência do campo elétrico de gate na energia de adsorção e na quantidade de carga transferida devido à adsorção do $\mathrm{H}_{2}$ no grafeno suspenso e depositado no $\mathrm{SiO}_{2}$ amorfo na configuração sobre. O objetivo desse estudo é investigar a possibilidade de o campo elétrico de gate aumentar a quantidade de carga transferida entre o $\mathrm{H}_{2}$ e o restante do sistema nesses dois casos.

Na Figura 4.6(a) é apresentada a curva de $E_{a d}$ em função do campo elétrico de gate. São observadas variações maiores nos valores de $E_{a d}$ no sistema formado pela molécula $\mathrm{H}_{2}$ adsorvida no grafeno depositado no $\mathrm{SiO}_{2}$ amorfo em comparação com o grafeno suspenso. Essa diferença pode ser compreendida a partir da polarização das cargas do grafeno depositado no $\mathrm{SiO}_{2}$ amorfo: cargas são transferidas do substrato para o grafeno ou do grafeno para o substrato (dependendo do sentido do campo elétrico), aumentando a interação entre os dipolos elétricos da molécula e do grafeno. 


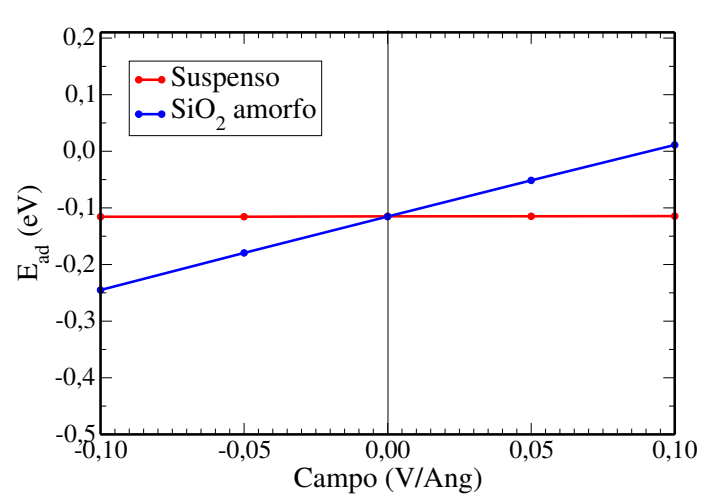

(a) Energias de adsorção.

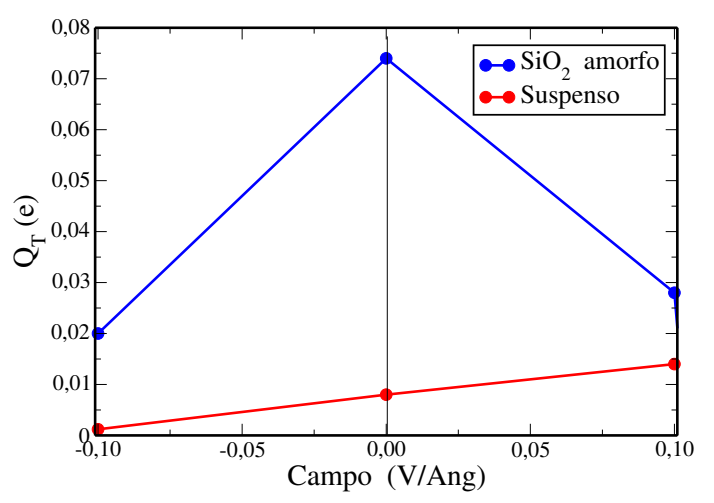

(b) Quantidade de carga transferida.

Figura 4.6: (a) Curva $E_{a d}$ em função do campo elétrico de gate com a molécula adsorivda sobre o grafeno suspenso e depositado no $\mathrm{SiO}_{2}$ amorfo(configuração sobre); (b) variação de $Q_{T}$ em função do campo elétrico de gate nesses dois sistemas.

O campo elétrico de gate diminui a energia de adsorção da molécula $\mathrm{H}_{2}$ adsorvida pelo grafeno depositado no $\mathrm{SiO}_{2}$ amorfo, mas não há um aumento significativo na quantidade de carga transferida entre a molécula e o restante do sistema (dentro do intervalo de módulos de campo elétrico de gate aqui considerados), como pode ser observado na Figura 4.6(b). Portanto, a adsorção do $\mathrm{H}_{2}$ na região intersticial (entre o grafeno e o $\mathrm{SiO}_{2}$ amorfo) é o fator predominante na transferência de carga, e o campo elétrico não possui uma influência significativa na transferência de carga. 


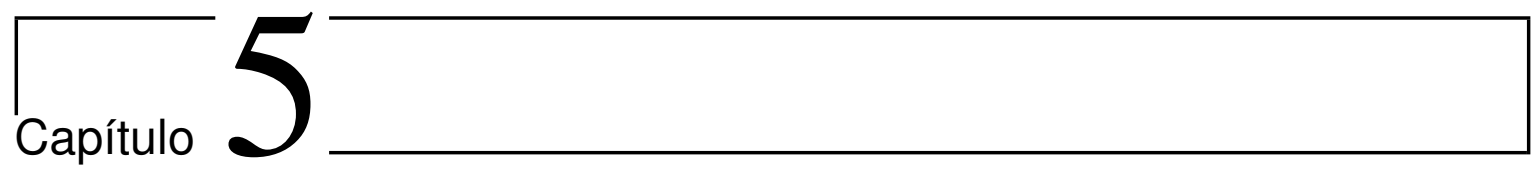

\section{CONSIDERAÇÕES FINAIS.}

Neste trabalho foram realizadas cálculos de primeiros princípios para investigar as propriedades eletrônicas de dois nanossistemas à base de nanotubos de carbono e o grafeno. Esses materiais possuem propriedades interessantes para a construção de transistores de efeito de campo e sensores de gases, como a alta mobilidade e a sensibilidade. Por isso, esses materiais possuem potencial para serem substitutos do silício, utilizado atualmente nesses dispositivos. No entanto, no atual estágio de desenvolvimento tecnológico, são encontradas dificuldades na utilização desses materiais em algumas situações. Na utilização dos nanotubos de carbono em transistores de efeito de campo, a junção metal-semicondutor pode, por exemplo, resultar em uma barreira Schottky, sendo ela indesejável na construção desse tipo de sistema. Além disso, a exposição do metal ao ambiente resulta na oxidação. que degrada a condutividade do sistema. Outro desafio é a utilização do grafeno na construção de sensores para a detecção de gases como o $\mathrm{H}_{2}$, pois as propriedades desse material não são significativamente alteradas com a adsorção dessas moléculas. No presente trabalho foram dadas contribuições para essa área de pesquisa ao investigar as propriedades eletrônicas de nanossistemas no âmbito destes desafios.

Um dos nanossistemas investigado é formado por uma nanotubo de carbono semicondutor acoplado a eletrodos de paládio encapsulado. De acordo com os trabalhos encontrados 
na literatura, a técnica de inserção de metais nos nanotubos de carbono permite realizar essa tarefa de maneira relativamente simples e em larga escala; e como foi mostrado no presente trabalho, a inserção do paládio no nanotubo de carbono é energeticamente favorável em relação aos sistemas isolados. Os metais encapsulados pelo nanotubo de carbono estão protegidos da oxidação, sendo essa uma vantagem dessa junção em relação aos sistemas não encapsulados. Além disso, a conexão do paládio ao nanotubo de carbono resulta em um contato ôhmico, sendo isso desejável para a construção de transistores de efeito de campo. Essa configuração do nanossistema pode ser interessante na construção de transistores de efeito de campo de alto desempenho. O potencial desse nanossistema para essa finalidade foi investigado no presente trabalho. Os resultados das simulaçõs computacionais realizadas para investigar as propriedades eletrônicas e de transporte desse nanossistema mostraram que:

1. estados metálicos do eletrodo se estendem pela região central e contribuem para a corrente elétrica do nanossistema;

2. os diferentes estados dos eletrodos influenciam de forma diferente a transmitância do nanossistema, pois possuem diferentes penetrações;

3. Investigou-se como a transmitância do nanossistema é influenciada quando modificasse o comprimento da região central. Foram observadas mudanças na polarização da corrente assim como na relação $I_{o n} / I_{o f f}$ que podem ser explicadas pela diminuição da influência dos estados dos eletrodos na região central;

4. e campo elétrico de gate aumenta a intensidade da corrente elétrica do nanossistema, como esperado. Entretanto, comprimentos de gate maiores são necessários para aplicações lógicas;

Os desenvolvimentos aqui realizados permitem determinar a variação da densidade de estados ao longo do sistema e, assim, estimar um comprimento da região semicondutora na qual a influência desses estados na transmitância possa ser desprezada. Como foi aqui 
mostrado, a comprimentos de $2,8 \AA ̊$ de gate, a contribuição desses estados à transmitância é significativa e que comprimentos maiores são necessários para que relações $I_{o n} / I_{o f f}$ suficientemente grandes sejam obtidas para a construção de transistores lógicos. Além disso, o presente trabalho mostrou que os diferentes estados dos eletrodos contribuem de forma distinta na transmitância do sistema. Este resultado sugere uma nova abordagem para futuros trabalhos no sentido de identificar os estados que mais se estendem pela região semicondutora, permitindo identificar metais mais apropriados para a construção de nanossistemas de menor comprimento de gate. De acordo com os resultados aqui obtidos, a intensidade da corrente elétrica — devido a um potencial de bias — pode ser variada por meio de um campo elétrico de gate. Considerando ainda o caráter metálico do eletrodo e o caráter ôhmico da junção paládio-nanotubo de carbono, o presente trabalho mostrou que esse nanossistema possui potencial em aplicações como transistor de efeito de campo.

O presente trabalho apresenta também contribuições para a construção de futuros sensores de $\mathrm{H}_{2}$ à base de grafeno, ao determinar grandezas físicas — como a energia de adsorção e a quantidade de carga transferida - para investigar a influência dos substratos $\mathrm{SiO}_{2}$ amorfo e $h$-BN na adsorção do $\mathrm{H}_{2}$ pelo grafeno. De acordo com trabalhos encontrados na literatura, a adsorção do $\mathrm{H}_{2}$ pelo grafeno não ocorre em condições normais de temperatura e pressão. Para que a adsorção seja possível nestas condições, energias de adsorção mais negativas — em comparação com a adsorção pelo grafeno suspenso - são necessárias. Foi mostrado aqui que a energia de adsorção da molécula de $\mathrm{H}_{2}$ adsorvida na interface grafeno/ $\mathrm{SiO}_{2}$ amorfo é três vezes menor em comparação com a adsorção pelo grafeno suspenso ou disposto sobre o substrato $h$-BN. Esse resultado mostra que a adsorção do $\mathrm{H}_{2}$ nessa região é energeticamente mais estável em comparação como a adsorção no grafeno suspenso. Porém, para que a adsorção da molécula $\mathrm{H}_{2}$ pelo grafeno possa ser detectada, é necessário que a quantidade de carga transferida $\left(Q_{T}\right)$ entre eles seja significativa. Para investigar isso, foi determinada a quantidade de carga transferida. A adsorção do $\mathrm{H}_{2}$ pelo grafeno suspenso resulta em uma $Q_{T}$ aproximadamente nula, não sendo possível a sua detecção. Porém, a 
adsorção do $\mathrm{H}_{2}$ na interface grafeno/ $\mathrm{SiO}_{2}$ amorfo, resulta em $Q_{T}$ uma ordem de grandeza maior em comparação com a adsorção no grafeno suspenso ou depositado no $h$-BN. Com a adsorção da molécula nessa região, há variações nas propriedades eletrônicas do grafeno como resultado da transferência de carga, como o deslocamento do cone de Dirac em relação ao nível de Fermi. Os resultados obtidos nesse estudo mostram, portanto, uma influência significativa do substrato $\mathrm{SiO}_{2}$ amorfo na adsorção do $\mathrm{H}_{2}$ na região intersticial, e que os resultados experimentais, obtidos por Silvestre et al.(13), podem ser estendidos para moléculas como o $\mathrm{H}_{2}$. Esse estudo pode levar a novas possibilidades, contribuindo para o desenvolvimento de futuros sensores de $\mathrm{H}_{2}$ à base de grafeno. 
$\varlimsup_{\text {Apêndice }}$

\section{TEORIA DO FUNCIONAL DA DENSIDADE}

Para as finalidades que se propõe nesse projeto, as metodologias a serem empregadas devem ser adequadas a uma descrição atomística de natureza quântica. Na atualidade, a teoria mais empregada no estudo de sistemas quânticos de muitos corpos acoplados é a Teoria do Funcional da Densidade (DFT). A Teoria do Funcional da Densidade é uma teoria da mecânica quântica utilizada para resolver equações tipo Schrödinger para sistemas de muitos corpos acoplados.

\section{A.1 Fundamentos do problema.}

Um sistema quântico é caracterizado pela função de onda $\Phi(\vec{r}, \vec{R})$, sendo essa a solução da equação Schrödinger independente do tempo:

$$
H(\vec{r}, \vec{R}) \Phi(\vec{r}, \vec{R})=E \Phi(\vec{r}, \vec{R})
$$

onde $H(\vec{r}, \vec{R})$ é o operador hamiltoniano do sistema interagente; $\{\vec{r}\}$ são as posições dos elétrons e $\{\vec{R}\}$ são as posições dos núcleos. O hamiltoniano de um sistema formado por um 
conjunto de átomos interagentes é:

$$
\hat{H}=\hat{T}_{e}+\hat{V}_{e-e}+\hat{V}_{e-n}+\hat{T}_{n}+\hat{V}_{n-n}
$$

onde $\hat{T}_{e}$ é a energia cinética dos elétrons; $\hat{T}_{n}$ é a energia cinética dos núcleos; $\hat{V}_{e-n}$ energia potencial de interação elétron-núcleo; $\hat{V}_{e-e}$ é energia potencial de interação elétron-elétron, e $\hat{V}_{n-n}$ é energia potencial de interação núcleo-núcleo.

Não existe uma solução analítica exata da equação (A.1) para o sistema descrito pela equação (A.2). Para a obtenção da solução $\Phi(\vec{r}, \vec{R})$ são realizadas aproximações, dentre elas a aproximação de Born e Oppenheimer(105).

\section{A.2 Aproximação de Bohr-Oppenheimer.}

Em um referencial inercial fixo no centro de massa do sistema formado por um conjunto de átomos interagentes, núcleos e elétrons possuem uma velocidade finita. Nesse referencial, o módulo da velocidade dos núcleos é menor que o módulo das velocidades dos elétrons, devido a diferença entre as massas desses. A variação das posições nucleares nesse referencial, resulta em um deslocamento dos elétrons (quase que) instantaneamente na direção das correspondentes posições nucleares. Esse fato possibilita o desacoplamento das funções de onda da parte eletrônica $\phi_{m}(\vec{r}, \vec{R})$ e nuclear $\Omega_{m}(\vec{R})$ do sistema (aproximação adiabática). A função de onda total pode assim ser escrita como um produto dessas funções:

$$
\Phi(\vec{r}, \vec{R})=\phi_{m}(\vec{r}, \vec{R}) \Omega_{m}(\vec{R})
$$

onde o índice $m$ se refere a uma dada configuração eletrônica.

Mesmo com a aproximação adiabática, existem ainda termos cruzados (funções de onda eletrônica com derivadas em relação as posições nucleares). Na aproximação de BohrOppenheimer os termos cruzados são desconsiderados nos cálculos de estrutura eletrônica pela mesma justificativa dada na aproximação adiabática. Essa nova aproximação resulta 
no desacoplamento completo dos sistemas eletrônico e nuclear e assim, os termos do hamiltoniano total podem ser agrupados em um hamiltoniano eletrônico $\hat{H}_{e}$ e um hamiltoniano nuclear $\hat{H}_{n}$, onde $\hat{H}_{e}=\hat{T}_{e}+\hat{V}_{e-e}+\hat{V}_{e x}$ (sendo que interação elétron núcleo é denominada potencial externo $\hat{V}_{e x}$ ) e $\hat{H}_{n}=\hat{T}_{n}+\hat{V}_{n-n}$. As auto-energias dos sistemas eletrônico e nuclear podem ser obitdas separadamente:

$$
\hat{H}_{e} \phi_{m}(\vec{r}, \vec{R})=E_{e} \phi_{m}(\vec{r}, \vec{R}) \quad \hat{H}_{n} \Omega_{m}(R)=E_{n} \Omega_{m}(R) .
$$

No entanto, a solução da equação de Schrödinger da parte eletrônica ainda apresenta termos acoplados, devido a interação elétron-elétron.

\section{A.3 Teoria do Funcional da Densidade.}

Na teoria do funcional da densidade, auto-energias do sistema eletrônico são funcionais da densidade eletrônica. A Teoria do Funcional da Densidade está baseada nos dois teoremas de Hohenberg e Kohn(106):

Teorema I - A densidade como variavel básica: a densidade eletrônica do estado fundamental $\rho_{0}(\vec{r})$ é uma função unívoca do potencial externo $\hat{V}_{e x}(\vec{r})$, a menos de uma constante aditiva.

Teorema I - Princípio variacional: A energia do estado fundamental obedece a um princípio variacional e é mínima para a densidade eletrônica do estado fundamental.

\section{A.4 Equações de Kohn-Sham (KS).}

O formalismo de Kohn-Sham (107) relaciona a energia eletrônica com a densidade eletrônica do estado fundamental do sistema, baseado na Teoria do Funcional da densidade. No formalismo de Kohn-Sham, o sistema é considerado como sendo constituido por elétrons não interagentes e que possui a mesma densidade eletrônica $\rho$ do sistema real de elétrons 
interagentes. Porém, é acrescentado um termo de correção à energia cinética dos elétrons.

$$
\hat{T}_{e}=\hat{T}_{S}+\hat{T}_{C}
$$

onde $\hat{T}_{S}$ é o operador energia cinética do sistema não interagente; e $\hat{T}_{C}$ é um termo de correção que se refere a energia de correlação. Nesse modelo, cada elétron interage com um campo médio devido a presença dos demais elétrons e o potencial externo.

O operador energia potencial de interação elétron-elétron também é escrito como uma soma de dois termos no formalismo de Kohn-Sham:

$$
\hat{V}_{e-e}=\hat{V}_{H}+\hat{V}_{X}
$$

onde $\hat{V}_{H}$ a o operador energia potencial de Hartree e $\hat{V}_{X}$ é o operador energia de troca. Os $\hat{T}_{C}$ e $\hat{V}_{X}$ são considerados em um único termo: o operador energia troca e correlação $\hat{E}_{X C}$. Esse termo é determinado por meio de aproximações apresentadas na Seção A.5.

No formalismo de Kohn-Sham, a energia eletrônica do sistema é escrita como:

$$
E[\rho]=T_{S}[\rho]+\int \rho(\vec{r}) V_{\text {ext }}(\vec{r}) d \vec{r}+\frac{1}{2} \iint \frac{\rho(\vec{r}) \rho\left(\vec{r}^{\prime}\right)}{\left|\vec{r}-\vec{r}^{\prime}\right|} d^{3} \vec{r} d^{3} \vec{r}^{\prime}+E_{X C}[\rho]
$$

A densidade eletrônica que minimiza a energia do sistema é obtida pelo processo variacional. Como o número de elétrons $N$ no sistema é fixo, a condição de mínimo para o funcional da energia $(\delta E[\rho(\vec{r})]=0)$ é restrita a um vínculo ( $N$ constante).

$$
\frac{\delta}{\delta \rho}\left\{E[p]-\mu\left[\int\left[\rho(\vec{r}) d^{3} r-N[\rho]\right]\right\}=0\right.
$$

onde $\mu$ é o multiplicador de Lagrange. O desenvolvimento da equação (A.8) resulta na equação:

$$
\frac{\delta T_{s}[\rho]}{\delta \rho(\vec{r})}+V_{e f}(\vec{r})-\mu=0
$$

onde $V_{e f}[\vec{r}]$ é o potencial efetivo:

$$
V_{e f}[\vec{r}]=V_{e x t}(\vec{r})+\frac{1}{2} \iint \frac{\rho(\vec{r}) \rho\left(\vec{r}^{\prime}\right)}{\left|\vec{r}-\vec{r}^{\prime}\right|} d^{3} \vec{r} d^{3} \vec{r}^{\prime}+\frac{\delta}{\delta \rho(\vec{r})} E_{X C}(\vec{r}) .
$$


A equação (A.9) possui a forma de uma equação tipo Schrödinger e a sua solução é obtida por meio da equação de Kohn-Sham de uma única partícula:

$$
\left[-\frac{1}{2} \nabla^{2}+\hat{V}_{e f}(\rho)\right] \phi_{k}^{K S}(r)=\varepsilon_{k}^{K S} \phi_{k}^{K S}(r)
$$

onde $\varepsilon_{k}=\mu ; \phi_{k}(\vec{r})^{K S}$ são os orbitais e $\varepsilon_{k}^{K S}$ os respectivos autovalores de Kohn-Sham. A partir da solução da equação (A.11) é determinada a densidade eletrônica de um sistema de partículas $N$ :

$$
\rho(\vec{r})=\sum_{k=1}^{\text {ocup }}\left|\phi_{k}^{K S *}(\vec{r}) \phi_{k}^{K S}(\vec{r})\right| .
$$

A energia do sistema no estado fundamental é obtida por meio da solução da equação (A.11) em um ciclo autoconsistente.

\section{A.5 Aproximações LDA e GGA.}

O termo $E_{X C}$ não possui uma representação analítica exata mas há aproximações para ele. As aproximações mais utilizadas são: aproximação da densidade local (LDA)(108) e a aproximação do gradiente generalizado (GGA)(109).

No funcional para as energias de troca e correlação LDA, o termo $E_{X C}$ é considerado como sendo aproximadamente a energia de troca e correlação de um gás homogêneo de elétrons com a mesma densidade eletrônica do sistema em um elemento de volume $d^{3} r$, ou seja:

$$
E_{X C}[\rho] \simeq E_{X C}^{L D A}[\rho]=\int \rho(\vec{r}) \varepsilon_{X C}^{\text {homogêneo }}(\rho) d r
$$

onde $\varepsilon_{X C}^{\text {homogêneo }}(\rho)$ é a energia de troca e correlação de um gás homogêneo de elétrons com densidade eletrônica $\rho$.

No funcional para energia de troca e correlação GGA, é considerado também o gradiente da densidade eletrônica em cada elemento de volume $d^{3} r$. 


\section{A.6 Teoria do pseudopotencial.}

A solução das equações de Kohn-Sham pode ser obtida com menor custo computacional por meio da utilização de pseudopotenciais. A teoria dos pseudopotenciais está baseada no fato de que elétrons que estão próximos aos núcleos não participam diretamente das ligações químicas. A estrutura eletrônica é então dividida em duas regiões: a região de caroço e a de valência. Os elétrons de valência participam diretamente das ligações químicas e determinam as propriedades eletrônias do sistema. Eles interagem com um e por isso os orbitais correspondentes apresentam formas mais suaves. Na teoria do pseudopotencial, o potencial externo $\hat{V}_{\text {ext }}$ da equação de Kohn-Sham é reescrito a fim de incluir o efeito da blindagem sobre os elétrons de valência e obter uma função de onda mais suave para a parte próxima ao núcleo, reduzindo o custo computacional.

A obtenção dos primeiros pseudopotenciais é atribuida ao trabalho de Phillips e Klein$\operatorname{man}(110)$. No trabalho Phillips e Kleinman(110) é utilizada uma combinação de funções de onda de caroço $\Phi_{c}$ e ondas planas $\phi_{v}$ para escrever a função de onda de valência $\Phi_{v}$ :

$$
\Phi_{v}=\phi_{v}+\sum_{c} a_{c} \Phi_{c}
$$

com a condição de que essa função de onda seja ortogonal aos estados de caroço. Essa função tem a propriedade de longe do núcleo predominar a parte da função de ondas planas, e perto predominar a parte das funções de caroço. As duas regiões são divididas por um raio de corte $r_{c}$. Modificações dessa proposição inicial culminaram com os pseudopotenciais de norma conservada que possuem as seguintes propriedades:

- autovalores de valência do sistema real e pseudoautovalores concordam para uma determinada configuração eletrônica;

- a função de onda real e a pseudofunção concordam a partir de um raio de corte $r_{c}$;

- as integrais da densidade de carga e da pseudodensidade de carga concordam entre si 
para $r<r_{c}$ em cada estado de valência;

- a derivada em relação a energia da derivada logarítmica da função real de da pseudofunção de onda concordam para $r>r_{c}$.

Os pseudopotenciais são determinados para átomos isolados, mas eles precisam ter a propriedade de transferibilidade, ou seja, devem reproduzir os potenciais em diferentes sistemas em que esse elemento é utilizado. Satisfazendo essa propriedade, é garantido que os orbitais de caroço permaneçam inalterados quando esse pseudopotencial é utilizado nos diferentes ambientes químicos. Para que isso ocorra, é preciso escolher adequadamente o raio de corte para cada orbital eletrônico.

O pseudopotencial é obtido a partir da solução da parte radial $^{1}$ da equação de Schrödinger all electron(ae) de um determinado elemento químico:

$$
\left(-\frac{1}{2} \frac{d^{2}}{d r^{2}}+V(r)+\frac{l(l+1)}{2 r^{2}}\right) r P_{l n}^{a e}(r)=\varepsilon_{l n} r P_{l n}^{a e},
$$

onde $V(r)$ é o potencial de interação elétron-núcleo.

Uma abordagem para a construção dos pseudopotenciais foi proposta por Kerker(111). Ele propõe uma função de onda radial analítica suave (ou seja, sem nós ou oscilações nessa região) para $r<r_{c}$ e que se reduza a função de onda do sistema all electron em $r>r_{c}$. Essa função de onda não é a função real, sendo ela uma pseudofunção:

$$
R_{l}^{P P}(r)=\left\{\begin{array}{rll}
R_{l}^{a e} & \text { se } & r \geq r_{c} \\
r^{l} \exp [p(r)] & \text { se } & r \leq r_{c}
\end{array}\right.
$$

onde $p(r)$ é um polinômio dado por:

$$
p(r)=a_{0}+a_{1} r+a_{2} r^{2}+a_{3} r^{3}+a_{4} r^{4} .
$$

Os coeficientes da equação (A.17) são determinados a partir da imposição de certas condições:

\footnotetext{
${ }^{1}$ A blindagem é função apenas de $r$ e por isso é considerada somente a solução radial $P_{l n}(r)^{a e}=r R_{l n}^{a e}(r)$.
} 
- o potencial deve ser finito em $r=0$;

- a carga dentro do raio de corte é conservada ou seja:

$$
\int d r\left|R_{l n}^{P P}(r)\right|^{2} r^{2}=\int_{0}^{r_{c}} d r\left|R_{l n}^{A E}(r)\right|^{2} r^{2}
$$

- a continuidade da pseudofunção de onda $R_{l}^{p p}(r)$ e de suas duas primeiras derivadas no ponto $r=r_{c}$ deve ser obedecida.

A equação de Schrödinger que possui como solução a pseudofunção é:

$$
\left(-\frac{1}{2} \frac{d^{2}}{d r^{2}}+V(r)+\frac{l(l+1)}{2 r^{2}}\right) r R_{l n}^{P P}(r)=\varepsilon_{l n} r R_{l n}^{P P},
$$

Por meio da inversão da equação (A.19):

$$
V_{l n}^{P P}(r)=\varepsilon_{l n}-\frac{l(l+1)}{r^{2}}+\frac{1}{r R_{l n}^{P P}(r)} \frac{d^{2}}{d r^{2}} r R_{l n}^{P P}(r),
$$

é obtido o pseudopotencial:

$$
V_{l n}^{P P}=\left\{\begin{aligned}
V^{A E}(r) & \text { se } \quad r \geq r_{c} \\
\varepsilon_{l n}+\frac{l+1}{r} \frac{p^{\prime \prime}(r)+\left[p^{\prime}(r)\right]^{2}}{2} \exp [p(r)] & \text { se } \quad r \leq r_{c}
\end{aligned}\right.
$$

Esse método foi generalizado por Troullier e Martins(50) no sentido de obter psudopotenciais mais suaves por meio da utilização de um polinômio de grau maior:

$$
p(r)=a_{0}+a_{2} r^{2}++a_{4} r^{4}+a_{6} r^{6}+a_{8} r^{8}+a_{10} r^{10}+a_{12} r^{12}
$$

onde os coeficientes $a_{i}$ são determinados empiricamente. A utilização desse polinômio resulta em maior velocidade de convergência da energia total do sistema em comparação com os cálculos utilizando o polinômio de menor grau. 


\section{A.7 Funções da base.}

No código SIESTA, orbitais moleculares são escritos em termos de uma combinação linear de orbitais atomicos (LCAO) (112). O número de orbitais $n$ na expansão é igual ao número de orbitais atômicos do sistema. Um orbital molecular $\phi_{i}$ é escrito como:

$$
\phi_{i}=\sum_{s=1}^{n} C_{s i} \varphi_{s}
$$

onde $\varphi_{s}$ são orbitais atômicos, sendo que cada um é multiplicado por um coeficiente $C_{s i}$, onde $s$ (numerado de 1 a $n$ ) representa cada orbital atômico. Em sistemas periódicos, $\phi_{i}$ será uma função de Bloch(113) somente se $C_{s i}=\frac{e^{i \vec{k} \cdot R}}{\sqrt{N}}$, onde o fator de normalização $N$ é o número de orbitais atômicos $n$. Os coeficientes $C_{s i}$ são as amplitudes das ondas planas nas posições $\vec{R}$ de cada átomo (112).

As funções $\varphi_{s}$ podem ser escritas em termos das coordenadas do espaço recíproco por meio de uma transformada de Fourier (114) Os vetores $\vec{k}$ utilizados para representar cada uma das funções na expansão podem ter módulo infinito para obter uma acuracia infinita na obtenção da solução $\varphi_{S}(\vec{k})$. No entanto, os coeficientes de Fourier decrescem com o aumento do módulo e assim, a expanção pode ser truncada em número finito de termos. A energia de corte (energy cut-off) define a frequência mais alta da componente de Fourier na expansão para determinar $\varphi_{s}(\vec{k})$. O domínio de $\varphi_{s}$ (de 0 até a frequência de corte) pode ser discretizado por meio de um grid no espaço recíproco. O espaçamento do grid no espaço recíproco na primeira zona de Brillouin, é uniformemente distribuido conforme o esquema de Monkhorst e Pack(51).

As funções $\varphi_{s}$ são escritas em termos de um produto dos harmônicos esféricos $Y_{l m} \mathrm{e}$ pela parte radial $R_{l n}$ :

$$
\varphi_{l m n}=R_{l n} Y_{l m}
$$

A parte radial pode também ser expandida em um conjunto de funções gaussianas. Caso 
seja ulizada apenas uma função gaussiana, a base é denominada $S Z$ ( $\zeta$ simples). Uma melhor descrição da parte radial é obtida, considerando duas funções gaussinaas na expansão sendo a base denominada $D Z$ ( $\zeta$ duplo). Orbitais de elétrons polarizados podem também ser utilizados na expansão para descrever sistemas com momento magnético resultante finito.

O domínio da função gaussiana é infinito. Para melhorar a performace computacional, é imposto um limite a esse domínio por meio do energy shift. Cada orbital atômico possui um alcance $r$ diferente. A utilização do energy shift (115) é um modo de definir um raio de corte a todos os orbitais atômicos por meio de um único parâmetro. Para que seja mantida a normalização da função de onda do orbital em questão, deve haver um aumento na energia para compensar a redução ocorrida pelo seu "corte". A utilização do energy shift para delimitar o alcance de cada orbital ao invés de um raio de corte é um modo eficiente de impor o confinamento. 


\section{TÉCNICA DAS FUNÇÕES DE GREEN FORA DO EQUILÍBRIO.}

A técnica das Funções de Green Fora do Equilíbrio é amplamente utilizada (116, 117, 118, 119) para determinar as propriedades de transporte eletrônico em sistemas em nanoescala fora do equilíbrio. Aqui será apresentado resumidamente o desenvolvimento matemático do método das Funções de Green Fora do Eequilíbrio (NEGF), tendo como base a referência(120).

O sistema utilizado no estudo do transporte eletrônico é constituído por uma região de espalhamento $S$ acoplada a duas regiões denominadas eletrodo direito $R$ (Right) e esquerdo $L$ (Left) tendo potenciais químicos $\mu_{1}$ e $\mu_{2}$, respectivamente. Se os potenciais químicos forem diferentes esse sistema está fora do equilíbrio, resultando em um transporte eletrônico. Os eletrodos são estruturas periódicas e infinitas. Nesse modelo eletrodos são considerados metálico e eles não são perturbados nem pela saída ou entrada de elétrons nem pela estrutura eletrônica da região de espalhamento. A corrente eletrônica na região de espalhamento é descrita em termos da probabilidade de transmissão de um elétron, sendo estabelecida uma relação dessa com a condutância sendo essa uma relação linear. 


\section{B.1 Funções de Green Fora do Equilíbrio.}

A equação de Schrödinger de um sistema fora de equilíbrio, devido a uma pertubração $\lambda$ é:

$$
\hat{H}|\Psi\rangle=E|\Psi\rangle+\lambda|\Psi\rangle=E|\Psi\rangle+|\lambda\rangle
$$

onde a atuação de $\lambda$ gerou o estado $|\lambda\rangle$. Isolando a parte perturbada:

$$
|\Psi\rangle=-(E-H)^{-1}|\lambda\rangle \Longrightarrow|\Psi\rangle=-G(E)|\lambda\rangle
$$

sendo que a função $G(E)$, definida por

$$
(E-H) G(E)=\mathbf{1}
$$

é a Função de Green. A solução $|\Psi\rangle$ do sistema será obtida após o conhecimento da Função de Green. Para conhecer essa função, é necessário primeiro conhecer como o hamiltoniano atua sobre a função $|\Psi\rangle$. O hamiltoniana da região $L$ é $H_{1}$; da região $S$ é $H_{c}$ e da região $R$ é $H_{2}$. Esses hamiltonianos satisfazem a equação de autovalores:

$$
\begin{aligned}
& H_{1}\left|\Psi_{1}\right\rangle=E_{1}\left|\Psi_{1}\right\rangle \\
& H_{c}\left|\Psi_{c}\right\rangle=E_{c}\left|\Psi_{c} 1\right\rangle \\
& H_{2}\left|\Psi_{2}\right\rangle=E_{2}\left|\Psi_{2}\right\rangle .
\end{aligned}
$$

Existem ainda os hamiltonianos de acoplamento da região $L$ com a região $S$, denotado por $\tau_{1}$; e de acoplamento da região $R$ com a região $S$, denotado por $\tau_{2}$. Esses termos são representados pelo hamiltoniano total $H_{T}$ na equação de autovalores:

$$
\left(\begin{array}{ccc}
H_{1} & \tau_{1}^{\dagger} & 0 \\
\tau_{1} & H_{c} & \tau_{2} \\
0 & \tau_{2}^{\dagger} & H_{2}
\end{array}\right)\left(\begin{array}{l}
\left|\Psi_{1}\right\rangle \\
\left|\Psi_{c}\right\rangle \\
\left|\Psi_{2}\right\rangle
\end{array}\right)=E\left(\begin{array}{l}
\left|\Psi_{1}\right\rangle \\
\left|\Psi_{c}\right\rangle \\
\left|\Psi_{2}\right\rangle
\end{array}\right)
$$


Da equação (B.7), a função $\left|\Psi_{2}\right\rangle$ pode ser determinada:

$$
\begin{array}{r}
H_{2}\left|\Psi_{2}\right\rangle+\tau_{2}^{\dagger}\left|\Psi_{c}\right\rangle=E\left|\Psi_{2}\right\rangle \\
H_{2}\left|\Psi_{2}\right\rangle=\left(E-H_{2} a\right)^{-1} \tau_{2}^{\dagger}\left|\Psi_{c}\right\rangle \quad \Longrightarrow \quad\left|\Psi_{2}\right\rangle=g_{2}(E) \tau_{2}^{\dagger}\left|\Psi_{c}\right\rangle
\end{array}
$$

onde $g_{2}(E)$ é a Função de Green do eletrodo $R$ isolado. A função $\left|\Psi_{1}\right\rangle$ pode ser determinada de forma semelhante, resultando:

$$
\left|\Psi_{1}\right\rangle=g_{1}(E) \tau_{1}^{\dagger}\left|\Psi_{c}\right\rangle
$$

onde $g_{1}(E)$ é a Função de Green do eletrodo $L$ isolado. O próximo passo é determinar a Função de Green. Considerando a definição da Função de Green (B.3) na forma matricial:

$$
\left(\begin{array}{ccc}
E-H_{1} & -\tau_{1}^{\dagger} & 0 \\
-\tau_{1} & E-H_{c} & -\tau_{2} \\
0 & -\tau_{2}^{\dagger} & E-H_{2}
\end{array}\right)\left(\begin{array}{ccc}
G_{11} & G_{1 c} & G_{12} \\
G_{c 1} & G_{c c} & G_{c 2} \\
G_{21} & G_{2 c} & G_{22}
\end{array}\right)=\left(\begin{array}{ccc}
1 & 0 & 0 \\
0 & 1 & 0 \\
0 & 0 & 1
\end{array}\right)
$$

A Função de Green da região $S$ é obtida pela multiplicação da matriz $H_{T}$ pela segunda coluna de $G(E)$ da equação (B.11), resultando no sistema de equações:

$$
\begin{gathered}
\left(E-H_{1}\right) G_{1 c}-\tau_{1}^{\dagger} G_{c c}=0 \\
-\tau_{1} G_{1 c}+\left(E-H_{1}\right) G_{c c}-\tau_{2} G_{2 c}=1 \\
\left(E-H_{1}\right) G_{2 c}-\tau_{2}^{\dagger} G_{c c}=0 .
\end{gathered}
$$

Da soma das equações (B.12) e (B.14) resulta que:

$$
G_{1 c}=g_{1} \tau_{1}^{\dagger} G_{c c} \quad \text { e } \quad G_{2 c}=g_{2} \tau_{2}^{\dagger} G_{c c} .
$$

A substituição da equação (B.15) em (B.13) resulta no sistema de equações:

$$
\begin{gathered}
-\tau_{1} g_{1}^{\dagger} G_{c c}-\left(E-H_{c}\right) G_{c c}-\tau_{2} g_{2} \tau_{2}^{\dagger} G_{c c}=1 \\
G_{c c}=\left(E-H_{c}-\tau_{1} g_{1} \tau_{1}^{\dagger}-\tau_{2} g_{2} \tau_{2}^{\dagger}\right)^{-1}
\end{gathered}
$$




$$
G_{c c}=\left(E-H_{c}-\Sigma_{1}-\Sigma_{2}\right)^{-1},
$$

onde $\Sigma_{1} \equiv \tau_{1} g_{1} \tau_{1}^{\dagger}$ e $\Sigma_{2} \equiv \tau_{2} g_{2} \tau_{2}^{\dagger}$ são as auto-energias dos contatos.

\section{B.1.1 Função espectral.}

Para auxiliar na solução da equação se Schrödinger do sistema fora do equilíbrio e dar sequência ao desenvolvimento do formalismo das Funções de Green Fora do Equilíbro, considera-se a definição da função espectral:

$$
A=i\left(G-G^{\dagger}\right)
$$

A solução $|\Psi\rangle$ da equação (B.2) é formada por duas soluções independentes: uma função de onda avançada $|\Psi\rangle^{A}$ e uma função de onda retardada $|\Psi\rangle^{R}$, definidas por:

$$
\begin{gathered}
|\Psi\rangle^{R}=-G|\lambda\rangle \\
|\Psi\rangle^{A}=-G^{\dagger}|\lambda\rangle .
\end{gathered}
$$

Subtraindo (B.20) de (B.21) resulta que $|\Psi\rangle^{R}-|\Psi\rangle^{A}=\left(G-G^{\dagger}\right)|\lambda\rangle=-i A|\lambda\rangle$. Multiplicando esse resultado por $(E-H)$, resulta que:

$$
\begin{gathered}
(E-H)\left(|\Psi\rangle^{R}-|\Psi\rangle^{A}\right)=(E-H)\left(G-G^{\dagger}\right)|\lambda\rangle=(I-I)|\lambda\rangle=0 \\
(E-H)(i A|\lambda\rangle)=0 \quad \Longrightarrow \quad H(A|\lambda\rangle)=E|\lambda\rangle
\end{gathered}
$$

A função $|\Psi\rangle=A|\lambda\rangle$ é uma solução da equação de Schrödinger para qualquer vetor $|\lambda\rangle$. Utilizando a função espectral é possível agora obter a solução da equação de Schrödinger, uma vez que a função $|\lambda\rangle$ é conhecida. Para obter essa solução, a Função de Green é alterada por meio da adição de um termo imaginário $\Delta$ aproximadamente nulo e por meio de uma 
expansão em termos da base de $|\Psi\rangle$ utilizando a relação de complitude:

$$
G=\frac{1}{E-H} \simeq \frac{1}{E+i \Delta-H}=\sum_{k} \frac{|k\rangle\langle k|}{\varepsilon_{k}+i \Delta-H},
$$

onde $|k\rangle$ são autovetores de $H$ e $\varepsilon_{k}$ os autovalores correspondentes. Substituindo a equação (B.24) na equação (B.19):

$$
A=i \sum_{k}|k\rangle\left\langle k\left|\left(\frac{1}{E+i \Delta-H}-\frac{1}{E-i \Delta-H}\right)=i \sum_{k}\right| k\right\rangle\langle k|\left(\frac{2 \Delta}{\left(E-\varepsilon_{k}\right)^{2}+\Delta^{2}}\right) .
$$

No limite $\Delta \rightarrow 0$ :

$$
A=\lim _{\Delta \rightarrow 0} i \sum_{k}|k\rangle\left\langle k\left|\left(\frac{2 \Delta}{\left(E-\varepsilon_{k}\right)^{2}+\Delta^{2}}\right) \simeq 2 \pi i \sum_{k}\right| k\right\rangle\langle k| \delta\left(E-\varepsilon_{k}\right),
$$

onde foi utilizada a definição da função Delta de Dirac. A solução da equação de Schrödinger é obtida substituindo o resultado da equação (B.26) na equação $|\Psi\rangle=A|\lambda\rangle$.

Outra função utilizada no formalismo da técnica das Funções de Green Fora do Equilíbrio é a função acoplamento $\Gamma(E)$, definida por:

$$
\Gamma(E)=i\left(\Sigma(E)-\Sigma^{\dagger}(E)\right)
$$

Lembrando que a função espectral é dada por:

$$
A=i\left(G-G^{\dagger}\right)
$$

e multiplicando-se dos dois lados por $\tau$ e $\tau^{\dagger}$, obtém-se que:

$$
\tau A \tau^{\dagger}=i\left(\tau G \tau^{\dagger}-\tau G^{\dagger} \tau^{\dagger}\right)=i\left(\Sigma-\Sigma^{\dagger}\right)=\Gamma \Rightarrow \tau A \tau^{\dagger}=\Gamma
$$

Essa função será utilizada na determinação da corrente elétrica na Seção B.1.4. 


\section{B.1.2 Função de onda resposta.}

A diferença de potencial químico dos eletrodos resulta no transporte de cargas. Estados ocupados por essas cargas correspondem as funções de onda de entrada dos eletrodos. Considerando que no contato 1 (isolado do restante do sistema) a função de onda $\left|\Psi_{1 n}\right\rangle$ (onde o índice 1 se refere ao eletrodo $L$ e $n$ é um nível quântico) e que ela é totalmente refletida pela borda do contato. Com o acoplamento do eletrodo à região espalhadora $S$, a onda incidente gera uma função resposta $\left|\Psi_{R}\right\rangle$ no restante do sistema e é espalhada inclusive por ele mesmo. A função de onda total, que se propaga pelo sistema, é dado então por $|\Psi\rangle=\left|\Psi_{1 n}\right\rangle+\left|\Psi_{R}\right\rangle$. Esse auto-estado também é auto-estado do hamiltoniano total:

$$
H_{T}\left(\left|\Psi_{1, n}\right\rangle+\left|\Psi_{R}\right\rangle\right)=E\left(\left|\Psi_{1, n}\right\rangle+\left|\Psi_{R}\right\rangle\right)
$$

e como $H_{1}$ e $\tau_{1}$ só atuam no auto-estado $\left|\Psi_{1, n}\right\rangle$ e que $H_{T}$ atua em $\left|\Psi_{R}\right\rangle$ (pois essa função está em todo o sistema), pode-se escrever então que:

$$
H_{1}\left|\Psi_{1, n}\right\rangle+\tau_{1}\left|\Psi_{1, n}\right\rangle+H_{T}\left|\Psi_{R}\right\rangle=E\left|\Psi_{1, n}\right\rangle+E\left|\Psi_{R}\right\rangle
$$

Considerando que $H_{1}\left|\Psi_{1, n}\right\rangle=E\left|\Psi_{1, n}\right\rangle$, a função $\left|\Psi_{R}\right\rangle$ da equação (B.31) resulta:

$$
\left(E-H_{T}\right)\left|\Psi_{R}\right\rangle=\tau_{1}\left|\Psi_{1, n}\right\rangle \quad \Longrightarrow \quad\left|\Psi_{R}\right\rangle=G \tau_{1}\left|\Psi_{1, n}\right\rangle
$$

Como na região de espalhamento há somente a função de onda resposta, então:

$$
\left|\Psi_{R}\right\rangle=\left|\Psi_{c}\right\rangle=G_{c c} \tau_{1}\left|\Psi_{1, n}\right\rangle
$$

Com esse resultado, é possível determinar a função de onda $\left|\Psi_{2}\right\rangle$ substituindo o resultado da equação (B.33) na equação (B.8) em

$$
\left|\Psi_{2}\right\rangle=g_{2} \tau_{2}^{\dagger}\left|\Psi_{c}\right\rangle=g_{2} \tau_{2}^{\dagger} G_{c c} \tau_{1}\left|\Psi_{1, n}\right\rangle
$$

A função $\left|\Psi_{1}\right\rangle$ é determinada a partir da equação (B.10). Porém, nessa região há também 
a função de onda refletida, sendo necessário somá-la a função de onda $\left|\Psi_{1}\right\rangle$ :

$$
\begin{gathered}
\left|\Psi_{1}\right\rangle=g_{1} \tau_{1}^{\dagger}\left|\Psi_{c}\right\rangle+\left|\Psi_{1, n}\right\rangle=\left(1+g_{1} \tau_{1}^{\dagger} G_{c c} \tau_{1}\right)\left|\Psi_{1, n}\right\rangle \\
\left|\Psi_{1}\right\rangle=\left(1+g_{1} \tau_{1}^{\dagger} G_{c c} \tau_{1}\right)\left|\Psi_{1, n}\right\rangle .
\end{gathered}
$$

As funções $\left|\Psi_{1}\right\rangle,\left|\Psi_{2}\right\rangle$ e $\left|\Psi_{c}\right\rangle$ serão utilizadas na determinação de grandezas físicas como densidade de portadores de carga e a intensidade da corrente elétrica.

\section{B.1.3 Densidade de portadores de carga.}

A ocupação de estados de um gás de elétrons livres é dado pela estatísitica de FermiDirac. O número médio de elétrons no estado com energia $\varepsilon_{\alpha}$ do eletrodo $j$ com potencial químico $\mu_{j}$ é dado por:

$$
f_{j}\left(\varepsilon_{\alpha}, \mu_{j}\right)=\frac{1}{1+e^{\left(\varepsilon_{\alpha}-\mu_{j}\right) /\left(k_{B} T\right)}}, \quad i=1,2 .
$$

A densidade de portadores de carga é definida como:

$$
\rho=\sum_{\alpha} f\left(E_{\alpha}, \mu_{j}\right)\left|\Psi_{\alpha}\right\rangle\left\langle\Psi_{\alpha}\right|
$$

A somatória da equação (B.38) pode ser transformada em uma integral no limite de $\alpha \rightarrow \infty$

$$
\rho=\int_{-\infty}^{\infty} f(E, \mu)\left|\Psi_{\alpha}\right\rangle\left\langle\Psi_{\alpha}\right| d N
$$

onde $d N$ é o número infinitesimal de estados e que pode ser escrito em termos da densidade de estados $d N=D(E) d E$, onde $D(E)$ é o número de estados por unidade de energia. A densidade de portadores de carga na região $S$ devido ao eletrodo $j$ é dada por:

$$
\rho_{c}^{j}=\int_{-\infty}^{\infty} f\left(E, \mu_{j}\right)\left|\Psi_{c}\right\rangle\left\langle\Psi_{c}\right| D(E) d E
$$


Substituindo o resultado da equação (B.33) na equação (B.40), resulta:

$$
\begin{gathered}
\rho_{c}^{j}=\int_{-\infty}^{\infty} d E f\left(E, \mu_{j}\right) \sum_{k} D(E) G_{c c} \tau_{j}\left|\Psi_{i, k}\right\rangle\left\langle\Psi_{i, k}\right| \tau_{j}^{\dagger} G_{c c}^{\dagger} \\
\rho_{c}^{j}=\int_{-\infty}^{\infty} d E f\left(E, \mu_{j}\right) G_{c c} \tau_{j}\left(\sum_{k} D(E) G_{c c} \tau_{j}\left|\Psi_{i, k}\right\rangle\left\langle\Psi_{i, k}\right|\right) \tau_{j}^{\dagger} G_{c c}^{\dagger} .
\end{gathered}
$$

O termo entre parênteses pode ser identificado como a função espectral para o contato $j$, sendo denotado por $a_{j}$ :

$$
\rho_{c}^{j}=\int_{-\infty}^{\infty} d E f\left(E, \mu_{j}\right) G_{c c} \tau_{j}\left(\frac{a_{j}}{2 \pi}\right) \tau_{j}^{\dagger} G_{c c}^{\dagger} .
$$

O resultado da equação (B.29) pode ser utilizado para simplicar o resultado da equação (B.43):

$$
\rho_{c}^{j}=\frac{1}{2 \pi} \int_{-\infty}^{\infty} d E f\left(E, \mu_{j}\right) G_{c c} \Gamma_{j} G_{c c}^{\dagger}
$$

Considerando ainda que há degenerescência de spin no sistema, a densidade será o dobro do resultado da (B.44):

$$
\rho_{c}^{j}=\frac{2}{2 \pi} \int_{-\infty}^{\infty} d E f\left(E, \mu_{j}\right) G_{c c} \Gamma_{j} G_{c c}^{\dagger}
$$

Na região $S$ há a contribuição dos dois eletrodos na densidade de portadores de carga. Assim, a densidade eletrônica total será:

$$
\rho=\frac{2}{2 \pi} \int_{-\infty}^{\infty} d E \sum_{i=1}^{2} f\left(E, \mu_{j}\right) G_{c c} \Gamma_{j} G_{c c}^{\dagger}
$$

A resolução dessa integral é realizada no plano complexo devido a parte imaginária da equação (B.24).

\section{B.1.4 Corrente de probabilidade.}

A intensidade da corrente de probabilidade é outra grandeza física de interesse no estudo do transporte eletrônico de um sistema. Para determinar essa grandeza, a onda $|\Psi\rangle$ é 
expressada como uma combinação linear de $\psi_{1}, \psi_{2}$ e $\psi_{c}$. Considerando essa função de onda no espaço recíproco $\Psi(k)$, a densidade de probabilidade é dada por:

$$
\rho_{P}=\langle\Psi \mid \Psi\rangle=\sum_{k}\langle\Psi \mid k\rangle\langle k \mid \Psi\rangle
$$

A densidade de probabilidade na região $S$ é conservada (não varia com o tempo) uma vez que o potencial químico é mantido constante. Derivando a equação (B.47) em relação ao tempo:

$$
\left.0=\sum_{k}\left(\frac{\partial\langle\psi|}{\partial t} k\right\rangle\langle k \mid \psi\rangle+\langle\psi \mid k\rangle\langle k| \frac{\partial|\psi\rangle}{\partial t}\right) .
$$

A região do canal atua somente no hamiltoniano $\mathbb{H}_{c}=H_{c}+\tau_{1}+\tau_{2}$. A atuação da parte temporal da equação de Schrödinger nos estados $\langle\psi|$ e $|\psi\rangle=$ resulta:

$$
\mathbb{H}_{c}|\psi\rangle=\frac{\hbar}{-i} \frac{\partial}{\partial t}|\psi\rangle \quad \mathbb{H}_{c}\langle\psi|=\frac{\hbar}{i} \frac{\partial}{\partial t}\langle\psi|
$$

Substituindo a equação (B.49) em (B.48), resulta:

$$
\begin{gathered}
0=\frac{i}{\hbar} \sum_{k}\left(\left\langle\psi|\mathbb{H}_{c} \underbrace{|k\rangle\langle k \mid \psi\rangle}_{\left|\psi_{c}\right\rangle}-\underbrace{\langle\psi \mid k\rangle\langle k|}_{\left\langle\psi_{c}\right|} \mathbb{H}_{c}| \psi\right\rangle\right)=\frac{i}{\hbar}\left(\left\langle\psi\left|\mathbb{H}_{c}\right| \psi_{c}\right\rangle-\left\langle\psi_{c}\left|\mathbb{H}_{c}\right| \psi\right\rangle\right) \\
=\frac{i}{\hbar}\left(\left\langle\psi\left|\left(H_{c}+\tau_{1}^{\dagger}+\tau_{2}^{\dagger}\right)\right| \psi_{c}\right\rangle-\left\langle\psi_{c}\left|\left(H_{c}+\tau_{1}+\tau_{2}\right)\right| \psi\right\rangle\right)= \\
=\underbrace{\frac{i}{\hbar}\left(\left\langle\psi_{1}\left|\tau_{1}^{\dagger}\right| \psi_{c}\right\rangle-\left\langle\psi_{c}\left|\tau_{1}\right| \psi_{1}\right\rangle\right)}_{-i_{1} / e}+\underbrace{\frac{i}{\hbar}\left(\left\langle\psi_{2}\left|\tau_{2}^{\dagger}\right| \psi_{c}\right\rangle-\left\langle\psi_{c}\left|\tau_{2}\right| \psi_{2}\right\rangle\right)}_{-i_{2} / e} .
\end{gathered}
$$

Aqui $-i_{1} / e$ é a densidade de corrente na região $S$ devido ao contato $1 ;-i_{2} / e$ é a densidade de corrente na região $S$ devido ao contato 2 e $i$ é um número imaginário. A intensidade da corrente elétrica devido ao eletrodo $j$ é obtida por meio da equação:

$$
i_{j}=\frac{-i e}{\hbar}\left(\left\langle\psi_{j}\left|\tau_{j}^{\dagger}\right| \psi_{c}\right\rangle-\left\langle\psi_{c}\left|\tau_{j}\right| \psi_{j}\right\rangle\right)
$$

Utilizando os resultados das equações (B.10), (B.8) e (B.33), a corrente devido ao ele- 
trodo 2 é dada por:

$$
\begin{gathered}
i_{2}=\frac{-i e}{\hbar}\left(\left\langle\psi_{2}\left|\tau_{2}^{\dagger}\right| \psi_{c}\right\rangle-\left\langle\psi_{c}\left|\tau_{2}\right| \psi_{2}\right\rangle\right)= \\
=\frac{-i e}{\hbar}\left(\left\langle\psi_{1, n}\left|\tau_{1}^{\dagger} G_{c c}^{\dagger} \tau_{2} g_{2}^{\dagger} \tau_{2}^{\dagger} G_{c c} \tau_{1}\right| \psi_{1, n}\right\rangle-\left\langle\psi_{1, n}\left|\tau_{1}^{\dagger} G_{c c}^{\dagger} \tau_{2} g_{2} \tau_{2}^{\dagger} G_{c c} \tau_{1}\right| \psi_{1, n}\right\rangle\right) \\
i_{2}=\frac{-i e}{\hbar}\left(\left\langle\psi_{1, n}\left|\tau_{1}^{\dagger} G_{c c}^{\dagger} \tau_{2}\left(g_{2}^{\dagger}-g_{2}\right) \tau_{2}^{\dagger} G_{c c} \tau_{1}\right| \psi_{1, n}\right\rangle\right)
\end{gathered}
$$

e utilizando a definição da função acoplamento (B.27), a equação (B.56) pode ser reescrita da seguinte forma:

$$
i_{2}=\frac{e}{\hbar}\left(\left\langle\psi_{1, n}\left|\tau_{1}^{\dagger} G_{c c}^{\dagger} \Gamma_{2} G_{c c} \tau_{1}\right| \psi_{1, n}\right\rangle\right)
$$

Para obter a corrente no eletrodo 2 é necessário integrar a corrente $i_{2}$ sobre todo o espectro de energia, além de somar sobre todos os estados $n$. Para obter a contribuição do eletrodo 2 à intensidade da corrente elétrica, é considerado a degenerescência de spin e também que os níveis preenchidos no eletrodo 2 são devido ao eletrodo 1 que obedece a distribuição de Fermi $f_{1}$ :

$$
\begin{gathered}
I_{2}=2 \frac{e}{\hbar} \int_{-\infty}^{\infty} d E f\left(E, \mu_{1}\right) \sum_{m, n} D(E)\left\langle\Psi_{1, n}\left|\tau_{1}^{\dagger}\right| m\right\rangle\left\langle m\left|G_{c c}^{\dagger} \Gamma_{2} \tau_{1}\right| \Psi_{1, n}\right\rangle \\
I_{2}=2 \frac{e}{\hbar} \int_{-\infty}^{\infty} d E f\left(E, \mu_{1}\right) \sum_{m} D(E)\left\langle m|G_{c c}^{\dagger} \Gamma_{2} G_{c c} \tau_{1} \underbrace{\sum_{n} D(E)\left|\Psi_{1, n}\right\rangle\left\langle\Psi_{1, n}\right|}_{a_{1} / 2 \pi} \tau_{1}^{\dagger}| m\right\rangle \\
I_{2}=2 \frac{e}{h} \int_{-\infty}^{\infty} d E f\left(E, \mu_{1}\right) \sum_{m} D(E)\left\langle m\left|G_{c c}^{\dagger} \Gamma_{2} G_{c c} \tau_{1} a_{1} \tau_{1}^{\dagger}\right| m\right\rangle \\
I_{2}=2 \frac{e}{h} \int_{-\infty}^{\infty} d E f\left(E, \mu_{1}\right) \operatorname{Tr}\left(G_{c c}^{\dagger} \Gamma_{2} G_{c c} \Gamma_{1}\right),
\end{gathered}
$$

onde $a_{1}$ é a função espectral do contato 1 isolado.

Para determinar a corrente $I_{1}$ devido ao eletrodo 1, é realizado o mesmo procedimento, porém esse resultado possui sinal contrário. A corrente total $I$ é obtida pela soma das duas contribuições:

$$
I=2 \frac{e}{h} \int_{-\infty}^{\infty} d E\left(f\left(E, \mu_{1}\right)-f\left(E, \mu_{2}\right)\right) \operatorname{Tr}\left(G_{c c}^{\dagger} \Gamma_{2} G_{c c} \Gamma_{1}\right)=
$$




$$
=2 \frac{e}{h} \int_{-\infty}^{\infty} d E\left(f\left(E, \mu_{1}\right)-f\left(E, \mu_{2}\right)\right) T(E)
$$

onde $T(E)$ é denominada transmitância, sendo ela interpretada como uma medida da permeabilidade do sistema ao fluxo de elétrons com energia $E$ provenientes dos eletrodos.

\section{B.2 Códigos computacionais utilizados nas simulações.}

\section{B.2.1 SIESTA.}

O código computacional SIESTA (Spanish Initiative for Eletronic Simulations with Thousands of Atoms - Iniciativa Espanhola para Simulações Eletrônicas com Milhares de Átomos) $(49,121)$ é utilizado para realizar cálculos de primeiros princípios da estrutura eletrônica e simulações de dinâmica molecular de sólidos e moléculas, resolvendo de maneira autoconsistente a teoria descrita no Apêndice A. Esse código utiliza as aproximações LDA e GGA para o potencial de troca e correlação; pseudopotenciais de norma conservada e uma base de funções de orbitais atômicos localizados. O SIESTA possui o código aberto, permetindo implementações como a realizada no código TRANSAMPA.

\section{B.2.2 TRANSAMPA.}

Diversos trabalhos utilizando o código TRANSAMPA já foram publicados(122, 123, 124 , 125, 126, 127, 128, 129), mostrando o sucesso da sua implementação. O código TRANSAMPA foi escrito pelo grupo de Simulação Aplicada a Materiais: Propriedades Atomísticas (SAMPA) para realizar cálculos de transporte eletrônico. Estes cálculos são realizados utilizando o formalismo da Teoria do Funcional da Densidade, acoplado à técnica das Funções de Green Fora do Equilibrio. As principais características do código são: cálculos autoconsistentes; aplicação de um potencial de bias entre a fonte e o dreno; correção de autointeração (SIC) (130); pontos $k$ transversais a direção de transporte; aplicação de um gate finito por meio da técnica multigrid e aplicação de um gate molecular finito (131). 


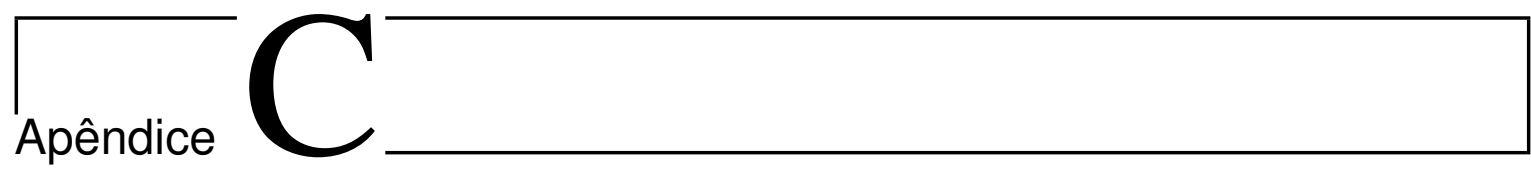

\section{PROGRAMA AWIREK}

O programa AwireK foi desenvolvido por Leonardo Abdalla e Alexsandro Kirch, originalmente para a geração de geometrias de nanofios estruturados. Posteriormente foram agregadas outras funcionalidades para a criação e tratamento de geometrias. Este programa encontra-se em processo de registro junto ao Instituto Nacional de Propriedade Industrial (INPI). Na Figura C.1 é apresentada a interface gráfica do programa.

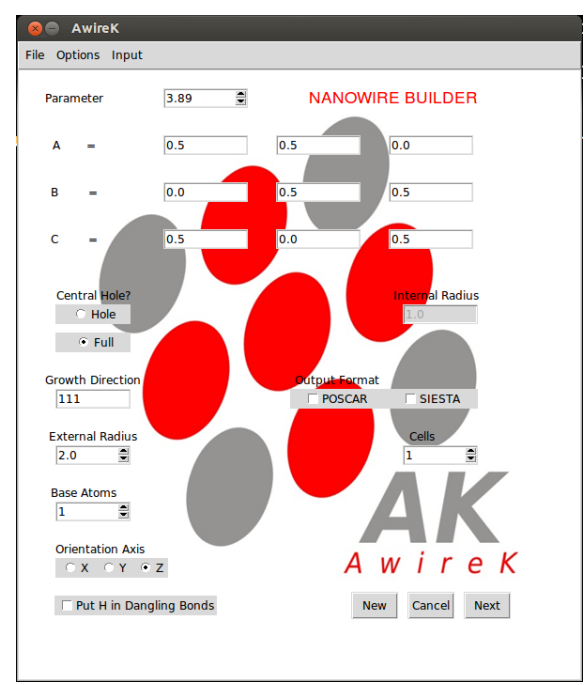

Figura C.1: Interface gráfica do AwireK.

A criação dos nanofios está baseada em cortes no bulk do material, em uma determinada direção de crescimento em relação aos planos de Miller. Parâmetros como diâmetro, comprimento e direção de crescimento podem ser configurados no programa. 


\section{Referências Bibliográficas}

1 IIJIMA, S. et al. Helical microtubules of graphitic carbon. nature, London, v. 354, n. 6348, p. 56-58, 1991.

2 GEIM, A.; NOVOSELOV, K. The rise of graphene. Nature materials, Nature Publishing Group, v. 6, n. 3, p. 183-191, 2007.

3 SHTOGUN, Y. V.; WOODS, L. M. Electronic structure modulations of radially deformed single wall carbon nanotubes under transverse external electric fields. The Journal of Physical Chemistry C, ACS Publications, v. 113, n. 12, p. 4792-4796, 2009.

4 BOLOTIN, K. et al. Temperature-dependent transport in suspended graphene. Physical review letters, APS, v. 101, n. 9, p. 96802, 2008.

5 BOLOTIN, K. et al. Ultrahigh electron mobility in suspended graphene. Solid State Communications, Elsevier, v. 146, n. 9, p. 351-355, 2008.

6 DU, X. et al. Approaching ballistic transport in suspended graphene. Nature Nanotechnology, Nature Publishing Group, v. 3, n. 8, p. 491-495, 2008.

7 BURGER, D.; GOODMAN, J. R. et al. Billion-transistor architectures. Computer, v. 30, n. 9, p. 46-48, 1997.

8 IEONG, M. et al. Silicon device scaling to the sub-10-nm regime. Science, American Association for the Advancement of Science, v. 306, n. 5704, p. 2057-2060, 2004.

9 SERVICE, R. Is silicon's reign nearing its end? Science, v. 323, p. 1000-1002, 2009.

10 FRANKLIN, A. D. et al. Sub-10 nm carbon nanotube transistor. Nano letters, ACS Publications, v. 12, n. 2, p. 758-762, 2012.

11 SCHEDIN, F. et al. Detection of individual gas molecules adsorbed on graphene. Nature materials, Nature Publishing Group, v. 6, n. 9, p. 652-655, 2007.

12 ULBRICHT, H.; MOOS, G.; HERTEL, T. Physisorption of molecular oxygen on single-wall carbon nanotube bundles and graphite. Physical Review B, APS, v. 66, n. 7, p. 075404, 2002. 
13 SILVESTRE, I. et al. Asymmetric effect of oxygen adsorption on electron and hole mobilities in bilayer graphene: Long-and short-range scattering mechanisms. ACS nano, ACS Publications, 2013.

14 VIANA, J. D. M.; FAZZIO, A.; CANUTO, S. Teoria quântica de moléculas e sólidos: Simulaçao computacional. São Paulo, Editora Livraria da Física, 2004.

15 NOVOSELOV, K. et al. Two-dimensional atomic crystals. Proceedings of the National Academy of Sciences of the United States of America, National Acad Sciences, v. 102, n. 30, p. 10451, 2005.

16 PEIERLS, R. Helv. Phys acta, v. 7, n. 81, 1934.

17 LANDAU, L. D. Zur theorie der phasenumwandlungen ii. Phys. Z. Sowjetunion, v. 11, p. 26-35, 1937.

18 SAITO, R. et al. Physical properties of carbon nanotubes. [S.1.]: World Scientific, 1998.

19 NETO, A. et al. The electronic properties of graphene. Reviews of Modern Physics, APS, v. 81, n. 1, p. 109, 2009.

20 CHARLIER, J.-C.; BLASE, X.; ROCHE, S. Electronic and transport properties of nanotubes. Reviews of modern physics, APS, v. 79, n. 2, p. 677, 2007.

21 BIERCUK, M. et al. Electrical transport in single-wall carbon nanotubes. Carbon Nanotubes, Springer, p. 455-493, 2008.

22 ODOM, T. W. et al. Atomic structure and electronic properties of single-walled carbon nanotubes. Nature, Nature Publishing Group, v. 391, n. 6662, p. 62-64, 1998.

23 NOVOSELOV, K. S. et al. Electric field effect in atomically thin carbon films. Science, American Association for the Advancement of Science, v. 306, n. 5696, p. 666-669, 2004.

24 LIN, Y. et al. 100-ghz transistors from wafer-scale epitaxial graphene. Science, American Association for the Advancement of Science, v. 327, n. 5966, p. 662-662, 2010.

25 KIM, K. et al. A role for graphene in silicon-based semiconductor devices. Nature, Nature Publishing Group, v. 479, n. 7373, p. 338-344, 2011.

26 BACHTOLD, A. et al. Logic circuits with carbon nanotube transistors. Science, American Association for the Advancement of Science, v. 294, n. 5545, p. 1317-1320, 2001.

27 RUMYANTSEV, S. et al. Selective gas sensing with a single pristine graphene transistor. Arxiv preprint arXiv:1204.5238, 2012.

28 DAN, Y. et al. Intrinsic response of graphene vapor sensors. Nano letters, ACS Publications, v. 9, n. 4, p. 1472-1475, 2009.

29 HILL, E.; VIJAYARAGHAVAN, A.; NOVOSELOV, K. Graphene sensors. Sensors Journal, IEEE, IEEE, n. 99, p. 1-1, 2011. 
30 MASSERA, E. et al. Gas sensors based on graphene. chimica oggi/Chemistry Today, v. 29, n. 1, 2011.

31 WEHLING, T. et al. Molecular doping of graphene. Nano letters, ACS Publications, v. 8 , n. 1, p. 173-177, 2008.

32 YAVARI, F. et al. High sensitivity gas detection using a macroscopic three-dimensional graphene foam network. Scientific reports, Nature Publishing Group, v. 1, 2011.

33 ZHENG, J. et al. Sub-10 nm gate length graphene transistors: Operating at terahertz frequencies with current saturation. Scientific reports, Nature Publishing Group, v. 3, 2013.

34 LU, J.; MIAO, J.; NORFORD, L. K. Localized synthesis of horizontally suspended carbon nanotubes. Carbon, Elsevier, 2013.

35 SZE, S.; NG, K. K. Metal-semiconductor contacts. Physics of Semiconductor Devices, Wiley Online Library, p. 134-196, 2006.

36 SHAN, B.; CHO, K. Ab initio study of schottky barriers at metal-nanotube contacts. Physical Review B, APS, v. 70, n. 23, p. 233405, 2004.

37 TUNG, R. T. The physics and chemistry of the schottky barrier height. Applied Physics Reviews, AIP Publishing, v. 1, n. 1, p. 011304, 2014.

38 JAVEY, A. et al. Advancements in complementary carbon nanotube field-effect transistors. In: IEEE. Electron Devices Meeting, 2003. IEDM'03 Technical Digest. IEEE International. [S.1.], 2003. p. 31-2.

39 MANN, D. et al. Ballistic transport in metallic nanotubes with reliable pd ohmic contacts. Nano Letters, ACS Publications, v. 3, n. 11, p. 1541-1544, 2003.

$40 \mathrm{KIM}$, W. et al. Electrical contacts to carbon nanotubes down to $1 \mathrm{~nm}$ in diameter. Applied Physics Letters, v. 87, p. 173101, 2005.

41 CHEN, Z. et al. The role of metal-nanotube contact in the performance of carbon nanotube field-effect transistors. Nano letters, ACS Publications, v. 5, n. 7, p. 1497-1502, 2005.

42 FRANK, S. et al. Carbon nanotube quantum resistors. Science, American Association for the Advancement of Science, v. 280, n. 5370, p. 1744-1746, 1998.

43 ZHU, W.; KAXIRAS, E. Schottky barrier formation at a carbon nanotube-metal junction. Applied physics letters, AIP, v. 89, n. 24, p. 243107-243107, 2006.

44 ZHU, W.; KAXIRAS, E. The nature of contact between pd leads and semiconducting carbon nanotubes. Nano letters, ACS Publications, v. 6, n. 7, p. 1415-1419, 2006.

45 HE, Y. et al. Schottky barrier formation at metal electrodes and semiconducting carbon nanotubes. Applied Physics Letters, AIP, v. 94, n. 9, p. 093107-093107, 2009.

46 DINIZ, E. M. et al. Bistability, softening, and quenching of magnetic moments in ni-filled carbon nanotubes. Physical Review B, APS, v. 81, n. 15, p. 153413, 2010. 
47 IVANOVSKAYA, V. V.; KÖHLER, C.; SEIFERT, G. 3d metal nanowires and clusters inside carbon nanotubes: Structural, electronic, and magnetic properties. Physical review $B$, APS, v. 75, n. 7, p. 075410, 2007.

48 KANG, Y.-J. et al. Electronic and magnetic properties of single-wall carbon nanotubes filled with iron atoms. Physical Review B, APS, v. 71, n. 11, p. 115441, 2005.

49 SOLER, J. M. et al. The siesta method for ab initio order-n materials simulation. Journal of Physics: Condensed Matter, IOP Publishing, v. 14, n. 11, p. 2745, 2002.

50 TROULLIER, N.; MARTINS, J. Efficient pseudopotentials for plane-wave calculations. Physical Review B, APS, v. 43, n. 3, p. 1993, 1991.

51 MONKHORST, H. J.; PACK, J. D. Special points for brillouin-zone integrations. Physical Review B, v. 13, n. 12, p. 5188-5192, 1976.

52 AGUILERA-GRANJA, F. et al. Metallic behavior of pd atomic clusters. Nanotechnology, IOP Publishing, v. 18, n. 36, p. 365706, 2007.

53 ALEXANDRE, S. S. et al. Comment on"magnetism in atomic-size palladium contacts and nanowires". Physical review letters, v. 96, n. 7, p. 79701, 2006.

54 KITTEL, C.; HELlWARTH, R. Introduction to solid state physics. Physics Today, v. 10, p. $43,1957$.

55 JONES, R. O.; GUNNARSSON, O. The density functional formalism, its applications and prospects. Reviews of Modern Physics, APS, v. 61, n. 3, p. 689, 1989.

56 TIAN, M. et al. Electrochemical growth of single-crystal metal nanowires via a two-dimensional nucleation and growth mechanism. Nano Letters, ACS Publications, v. 3, n. 7, p. 919-923, 2003.

57 WANG, Y. et al. Polyol synthesis of ultrathin pd nanowires via attachment-based growth and their enhanced activity towards formic acid oxidation. Advanced Functional Materials, Wiley Online Library, 2013.

58 TENG, X. et al. Synthesis of ultrathin palladium and platinum nanowires and a study of their magnetic properties. Angewandte Chemie, Wiley Online Library, v. 120, n. 11, p. 2085-2088, 2008.

59 SHINOHARA, T.; SATO, T.; TANIYAMA, T. Surface ferromagnetism of pd fine particles. Physical review letters, APS, v. 91, n. 19, p. 197201, 2003.

60 TANIYAMA, T.; OHTA, E.; SATO, T. Observation of 4d ferromagnetism in free-standing pd fine particles. EPL (Europhysics Letters), IOP Publishing, v. 38, n. 3, p. $195,1997$.

61 CHEN, H.; BRENER, N.; CALLAWAY, J. Electronic structure, optical and magnetic properties of fcc palladium. Physical Review B, APS, v. 40, n. 3, p. 1443, 1989.

62 AJAYAN, P. M. et al. Capillarity-induced filling of carbon nanotubes. Nature Publishing Group, 1993. 
63 BOGOMOLOV, V.; BOOK, D. Capillary effects in ultrathin channels. Soviet physics. Technical physics, American Institute of Physics, v. 37, n. 1, p. 79-82, 1992.

64 PEDERSON, M. R.; BROUGHTON, J. Q. Nanocapillarity in fullerene tubules. Physical review letters, APS, v. 69, n. 18, p. 2689, 1992.

65 KULSHRESTHA, N.; MISRA, A.; MISRA, D. Electrical transport and electromigration studies on nickel encapsulated carbon nanotubes: possible future interconnects. Nanotechnology, IOP Publishing, v. 24, n. 18, p. 185201, 2013.

66 CHEN, C.-W.; LEE, M.-H.; CLARK, S. Band gap modification of single-walled carbon nanotube and boron nitride nanotube under a transverse electric field. Nanotechnology, IOP Publishing, v. 15, n. 12, p. 1837, 2004.

67 LI, Y.; ROTKIN, S. V.; RAVAIOLI, U. Electronic response and bandstructure modulation of carbon nanotubes in a transverse electrical field. Nano Letters, ACS Publications, v. 3, n. 2, p. 183-187, 2003.

68 SILVA, L. da; FAGAN, S. B. First principles study of transverse electric fields on carbon nanotubes. In: AIP Conference Proceedings. [S.1.: s.n.], 2010. v. 1199, p. 341.

69 KINDER, J. M.; MELE, E. J. Formation of subgap states in carbon nanotubes due to a local transverse electric field. Physical Review B, APS, v. 76, n. 19, p. 195438, 2007.

70 KIM, Y.-H.; CHANG, K. Subband mixing rules in circumferentially perturbed carbon nanotubes: Effects of transverse electric fields. Physical Review B, APS, v. 64, n. 15, p. $153404,2001$.

71 ZHENG, F. et al. Scaling law of the giant stark effect in boron nitride nanoribbons and nanotubes. Physical Review B, APS, v. 78, n. 8, p. 085423, 2008.

$72 \mathrm{JR}, \mathrm{R}$. S. et al. Measuring the spin polarization of a metal with a superconducting point contact. Science, American Association for the Advancement of Science, v. 282, n. 5386, p. 85-88, 1998.

73 BUTLER, M. A. Fiber optic sensor for hydrogen concentrations near the explosive limit. Journal of the Electrochemical Society, The Electrochemical Society, v. 138, n. 9, p. L46-L47, 1991.

74 COHEN, A.; LARSEN, J. Explosive mechanism of the H2-O2 reaction near the second ignition limit. [S.1.], 1967.

75 CASSIDY, J.; PONS, S.; JANATA, J. Hydrogen response of palladium coated suspended gate field effect transistor. Analytical Chemistry, ACS Publications, v. 58, n. 8, p. 1757-1761, 1986.

76 MUBEEN, S. et al. Palladium nanoparticles decorated single-walled carbon nanotube hydrogen sensor. The Journal of Physical Chemistry C, ACS Publications, v. 111, n. 17, p. 6321-6327, 2007.

77 SUNDARAM, R. S. et al. Electrochemical modification of graphene. Advanced Materials, Wiley Online Library, v. 20, n. 16, p. 3050-3053, 2008. 
78 HENWOOD, D.; CAREY, J. D. Ab initio investigation of molecular hydrogen physisorption on graphene and carbon nanotubes. Phys. Rev. B, American Physical Society, v. 75, p. 245413, Jun 2007.

79 HAN, S. S.; LEE, H. M. Adsorption properties of hydrogen on $(10,0)$ single-walled carbon nanotube through density functional theory. Carbon, Elsevier, v. 42, n. 11, p. 2169-2177, 2004.

80 GIANNOZZI, P.; CAR, R.; SCOLES, G. Oxygen adsorption on graphite and nanotubes. The Journal of chemical physics, v. 118, p. 1003, 2003.

81 LAZI, P. et al. Role of van der waals interactions in adsorption of xe on cu(111) and pt(111). Phys. Rev. B, American Physical Society, v. 72, p. 245407, Dec 2005.

82 GRIMME, S. Semiempirical gga-type density functional constructed with a long-range dispersion correction. Journal of computational chemistry, Wiley Online Library, v. 27 , n. 15, p. 1787-1799, 2006.

83 MAPASHA, R. E.; UKPONG, A. M.; CHETTY, N. Ab initio studies of hydrogen adatoms on bilayer graphene. Physical Review B, APS, v. 85, n. 20, p. 205402, 2012.

84 DU, A.; SMITH, S. C. Van der waals corrected density functional theory: benchmarking for hydrogen nanotube and nanotube nanotube interactions. Nanotechnology, IOP Publishing, v. 16, n. 10, p. 2118, 2005.

85 RIGAMONTI, S.; PROETTO, C. R. Correlation kohn-sham potential for quasi-twodimensional electron gases. Phys. Rev. B, American Physical Society, v. 73, p. 235319, Jun 2006.

86 LUGO-SOLIS, A.; VASILIEV, I. Ab initio study of $\mathrm{k}$ adsorption on graphene and carbon nanotubes: Role of long-range ionic forces. Phys. Rev. B, American Physical Society, v. 76, p. 235431, Dec 2007.

87 LEENAERTS, O.; PARTOENS, B.; PEETERS, F. M. Adsorption of $\mathrm{h}_{2} \mathrm{O}, \mathrm{Nh}_{3}$, co, $\mathrm{No}_{2}$, and no on graphene: A first principles study. Phys. Rev. B, American Physical Society, v. 77, p. 125416, Mar 2008.

88 CABRIA, I.; LOPEZ, M.; ALONSO, J. Hydrogen storage in pure and li-doped carbon nanopores: Combined effects of concavity and doping. The Journal of chemical physics, v. 128, p. 144704, 2008.

89 TOZZINI, V.; PELLEGRINI, V. Prospects for hydrogen storage in graphene. Physical Chemistry Chemical Physics, Royal Society of Chemistry, v. 15, n. 1, p. 80-89, 2013.

90 GHOSH, A. et al. Uptake of $\mathrm{h} 2$ and co2 by graphene. The Journal of Physical Chemistry C, ACS Publications, v. 112, n. 40, p. 15704-15707, 2008.

91 HYNEK, S.; FULLER, W.; BENTLEY, J. Hydrogen storage by carbon sorption. International journal of hydrogen energy, Elsevier, v. 22, n. 6, p. 601-610, 1997.

92 YE, Y. et al. Hydrogen adsorption and cohesive energy of single-walled carbon nanotubes. Applied physics letters, v. 74, p. 2307, 1999. 
93 LIU, C. et al. Hydrogen storage in single-walled carbon nanotubes at room temperature. Science, American Association for the Advancement of Science, v. 286, n. 5442, p. 1127-1129, 1999.

94 NI, Z. et al. On resonant scatterers as a factor limiting carrier mobility in graphene. Nano letters, ACS Publications, v. 10, n. 10, p. 3868-3872, 2010.

95 CUONG, N. T.; OTANI, M.; OKADA, S. Semiconducting electronic property of graphene adsorbed on (0001) surfaces of sio $_{2}$. Physical review letters, APS, v. 106, n. 10, p. 106801, 2011.

96 HOFRICHTER, J. et al. Synthesis of graphene on silicon dioxide by a solid carbon source. Nano letters, ACS Publications, v. 10, n. 1, p. 36-42, 2009.

97 MIWA, R. et al. Doping of graphene adsorbed on the a-sio 2 surface. Applied Physics Letters, AIP, v. 99, n. 16, p. 163108-163108, 2011.

98 SCOPEL, W. L.; SILVA, A. J. da; FAZZIO, A. Amorphous hfo_ $\{2\}$ and hf_ $\{1-\mathrm{x}\}$ si_ $\{x\}$ o via a melt-and-quench scheme using ab initio molecular dynamics. Physical Review B, APS, v. 77, n. 17, p. 172101, 2008.

99 DEAN, C. et al. Boron nitride substrates for high-quality graphene electronics. Nature nanotechnology, Nature Publishing Group, v. 5, n. 10, p. 722-726, 2010.

100 USACHOV, D. et al. Quasifreestanding single-layer hexagonal boron nitride as a substrate for graphene synthesis. Physical Review B, APS, v. 82, n. 7, p. 075415, 2010.

101 WATANABE, K.; TANIGUCHI, T.; KANDA, H. Direct-bandgap properties and evidence for ultraviolet lasing of hexagonal boron nitride single crystal. Nature materials, Nature Publishing Group, v. 3, n. 6, p. 404-409, 2004.

102 PADILHA, J. E.; PONTES, R. B.; FAZZIO, A. Bilayer graphene on h-bn substrate: investigating the breakdown voltage and tuning the bandgap by electric field. Journal of Physics: Condensed Matter, IOP Publishing, v. 24, n. 7, p. 075301, 2012.

103 GIOVANNETTI, G. et al. Substrate-induced band gap in graphene on hexagonal boron nitride: Ab initio density functional calculations. Physical Review B, APS, v. 76, n. 7, p. 073103, 2007.

104 SACHS, B. et al. Adhesion and electronic structure of graphene on hexagonal boron nitride substrates. Physical Review B, APS, v. 84, n. 19, p. 195414, 2011.

105 BORN, M.; OPPENHEIMER, R. Zur quantentheorie der molekeln. Annalen der Physik, Wiley Online Library, v. 389, n. 20, p. 457-484, 2006.

106 HOHENBERG, P.; KOHN, W. Inhomogeneous electron gas. Physical Review, APS, v. 136, n. 3B, p. B864, 1964.

107 KOHN, W.; SHAM, L. et al. Self-consistent equations including exchange and correlation effects. [S.1.]: APS, 1965. 
108 CEPERLEY, D.; ALDER, B. Ground state of the electron gas by a stochastic method. Physical Review Letters, APS, v. 45, n. 7, p. 566-569, 1980.

109 PERDEW, J.; BURKE, K.; ERNZERHOF, M. Generalized gradient approximation made simple. Physical review letters, APS, v. 77, n. 18, p. 3865-3868, 1996.

110 PHILLIPS, J.; KLEINMAN, L. New method for calculating wave functions in crystals and molecules. Physical Review, APS, v. 116, n. 2, p. 287, 1959.

111 KERKER, G. Non-singular atomic pseudopotentials for solid state applications. Journal of Physics C: Solid State Physics, IOP Publishing, v. 13, n. 9, p. L189, 2000.

112 SLATER, J. C.; KOSTER, G. F. Simplified lcao method for the periodic potential problem. Physical Review, APS, v. 94, n. 6, p. 1498, 1954.

113 BLOCH, F. Über die quantenmechanik der elektronen in kristallgittern. Zeitschrift für physik, Springer, v. 52, n. 7-8, p. 555-600, 1929.

114 NIUKKANEN, A. Fourier transforms of atomic orbitals. i. reduction to fourdimensional harmonics and quadratic transformations. International journal of quantum chemistry, Wiley Online Library, v. 25, n. 6, p. 941-955, 1984.

115 ARTACHO, E. et al. Linear-scaling ab-initio calculations for large and complex systems. arXiv preprint cond-mat/9904159, 1999.

116 DEROSA, P. A.; SEMINARIO, J. M. Electron transport through single molecules: Scattering treatment using density functional and green function theories. The Journal of Physical Chemistry B, ACS Publications, v. 105, n. 2, p. 471-481, 2001.

$117 \mathrm{KONDO}, \mathrm{H}$. et al. Contact-structure dependence of transport properties of a single organic molecule between au electrodes. Physical Review B, APS, v. 73, n. 23, p. 235323, 2006.

118 WEI, Y. et al. Spin-valve effect in a carbon atomic wire. Physical Review B, APS, v. 70, n. 19, p. 193406, 2004.

119 KIM, W. Y.; KIM, K. S. Prediction of very large values of magnetoresistance in a graphene nanoribbon device. Nature nanotechnology, Nature Publishing Group, v. 3, n. 7 , p. 408-412, 2008.

120 PAULSSON, M. Non equilibrium green's functions for dummies: Introduction to the one particle negf equations. arXiv preprint cond-mat/0210519, 2002.

121 ARTACHO, E. et al. The siesta method; developments and applicability. Journal of Physics: Condensed Matter, IOP Publishing, v. 20, n. 6, p. 064208, 2008.

122 SOUZA, A. et al. Ab-initio calculations for a realistic sensor: A study of co sensors based on nitrogen-rich carbon nanotubes. AIP Advances, Author (s). This article is distributed under a Creative Commons Attribution 3.0 Unported License., v. 2, n. 3, p. 032115-032115, 2012. 
123 PONTES, R. B. et al. Ab initio calculations of structural evolution and conductance of benzene-1, 4-dithiol on gold leads. ACS nano, ACS Publications, v. 5, n. 2, p. 795-804, 2011.

124 LIMA, M. P.; SILVA, A. J. da; FAZZIO, A. Adatoms in graphene as a source of current polarization: Role of the local magnetic moment. Physical Review B, APS, v. 84, n. 24, p. 245411, 2011.

125 PONTES, R. B. et al. Adsorption of benzene-1, 4-dithiol on the au (111) surface and its possible role in molecular conductance. Journal of the American Chemical Society, ACS Publications, v. 128, n. 28, p. 8996-8997, 2006.

126 PADILHA, J. et al. Bilayer graphene dual-gate nanodevice: An ab initio simulation. Physical Review B, APS, v. 84, n. 11, p. 113412, 2011.

127 ROCHA, A. et al. Designing real nanotube-based gas sensors. Physical review letters, APS, v. 100, n. 17, p. 176803, 2008.

128 MENEZES, V. M. de et al. Electronic transport properties of ascorbic acid and nicotinamide adsorbed on single-walled carbon nanotubes. Chemical Physics Letters, Elsevier, v. 506, n. 4, p. 233-238, 2011.

129 PADILHA, J. E. et al. Ixv curves of boron and nitrogen doping zigzag graphene nanoribbons. International Journal of Quantum Chemistry, Wiley Online Library, v. 111, n. 7-8, p. 1379-1386, 2011.

130 FILIPPETTI, A.; SPALDIN, N. A. Self-interaction-corrected pseudopotential scheme for magnetic and strongly-correlated systems. Phys. Rev. B, American Physical Society, v. 67 , p. 125109, Mar 2003.

131 LIMA, M. P.; SILVA, A. J. R. da; FAZZIO, A. Adatoms in graphene as a source of current polarization: Role of the local magnetic moment. Phys. Rev. B, American Physical Society, v. 84, p. 245411, Dec 2011. 